\title{
Epitope-Based Vaccine of a Brucella abortus Putative Small RNA Target Induces Protection and Less Tissue Damage in Mice
}

OPEN ACCESS

Edited by: Ricardo Silvestre,

University of Minho, Portugal

Reviewed by:

Jieh-Juen Yu,

University of Texas at San Antonio,

United States

Rajesh Chhabra,

Lala Lajpat Rai University of Veterinary

and Animal Sciences, India

*Correspondence:

Leonardo Augusto de Almeida leonardo.almeida@unifal-mg.edu.br

Patrícia Paiva Corsetti ppcorsetti@hotmail.com

Specialty section: This article was submitted to Microbial Immunology, a section of the journal

Frontiers in Immunology

Received: 16 September 2021 Accepted: 03 December 2021

Published: 21 December 2021

Citation:

Oliveira KC, Brancaglion GA, Santos NCM, Araújo LP, Novaes E. Santos RL, Oliveira SC, Corsetti PP and de Almeida LA (2021) EpitopeBased Vaccine of a Brucella abortus Putative Small RNA

Target Induces Protection and

Less Tissue Damage in Mice.

Front. Immunol. 12:778475 doi: 10.3389/fimmu.2021.778475
Karen Cristina Oliveira ${ }^{1}$, Gustavo Andrade Brancaglion ${ }^{1}$, Natália C. M. Santos ${ }^{1}$, Leonardo P. Araújo ${ }^{1}$, Evandro Novaes ${ }^{2}$, Renato de Lima Santos ${ }^{3}$, Sergio Costa Oliveira ${ }^{4}$, Patrícia Paiva Corsetti ${ }^{1 *}$ and Leonardo Augusto de Almeida ${ }^{1 *}$

${ }^{1}$ Laboratory of Molecular Biology of Microorganisms, Federal University of Alfenas, Alfenas, Brazil, ${ }^{2}$ Department of Biology, Federal University of Lavras, Lavras, Brazil, ${ }^{3}$ Department of Clinic and Veterinary Surgery, Veterinary School, Federal University of Minas Gerais, Belo Horizonte, Brazil, ${ }^{4}$ Department of Biochemistry and Immunology, Federal University of Minas Gerais, Belo Horizonte, Brazil

Brucella spp. are Gram-negative, facultative intracellular bacteria that cause brucellosis in humans and animals. Currently available live attenuated vaccines against brucellosis still have drawbacks. Therefore, subunit vaccines, produced using epitope-based antigens, have the advantage of being safe, cost-effective and efficacious. Here, we identified $B$. abortus small RNAs expressed during early infection with bone marrow-derived macrophages (BMDMs) and an apolipoprotein $\mathrm{N}$-acyltransferase (Int) was identified as the putative target of the greatest expressed small RNA. Decreased expression of Int was observed during BMDM infection and the protein sequence was evaluated to rationally select a putative immunogenic epitope by immunoinformatic, which was explored as a vaccinal candidate. C57BL/6 mice were immunized and challenged with $B$. abortus, showing lower recovery in the number of viable bacteria in the liver, spleen, and axillary lymph node and greater production of $\lg G$ and fractions when compared to nonvaccinated mice. The vaccinated and infected mice showed the increased expression of TNF- $\alpha$, IFN- $\gamma$, and IL-6 following expression of the anti-inflammatory genes IL-10 and TGF- $\beta$ in the liver, justifying the reduction in the number and size of the observed granulomas. BMDMs stimulated with splenocyte supernatants from vaccinated and infected mice increase the CD86+ marker, as well as expressing greater amounts of iNOS and the consequent increase in NO production, suggesting an increase in the phagocytic and microbicidal capacity of these cells to eliminate the bacteria.

Keywords: Brucella abortus, vaccine, immune response, reverse vaccinology, brucellosis, apolipoprotein $\mathrm{N}$-acyltransferase 


\section{INTRODUCTION}

Brucellosis is a global zoonotic infectious disease caused by bacteria of the genus Brucella. The disease is a serious public health threat worldwide, particularly in developing countries of Central Asia, Africa, South America, and the Mediterranean region (1). Brucellosis affects mammals, causing abortion and infertility in affected animals. This infection can spread from animals to humans, mainly via the ingestion of unpasteurized milk or dairy products and, to a lesser extent, via direct contact with infected animals (2). In humans, brucellosis can cause a severe febrile disease with various clinical complications ranging from mild to severe symptoms including undulant fever, joint pain arthritis, endocarditis, and meningitis (3-5). The genus Brucella includes Gram-negative facultative intracellular bacteria from Alphaproteobacteria, and, currently, the genus consists of 12 species that are classified based on their host preferences (6). Although several Brucella species are potentially zoonotic agents, Brucella melitensis, Brucella abortus, and Brucella suis are considered the most pathogenic Brucella species that have a serious impact on public health and the livestock industry $(7,8)$, with $B$. abortus being the most widespread throughout the world, according to the World Health Organization (WHO) $(9,10)$. Since brucellosis is the most common zoonotic disease worldwide and has become a serious concern in recent years (11), the strategy used to control brucellosis depends mainly on the massive vaccination of domestic animals to prevent the disease from spreading to healthy animals and humans (12, 13). Almost all vaccines against Brucella spp. are live attenuated strains with extensive global use but with various drawbacks, such as pathogenicity to humans and residual virulence in animals, which can cause abortion, orchitis, and infertility (1416). Moreover, it is difficult to differentiate infected animals from vaccinated animals by serological tests. These drawbacks have prompted several research groups to attempt the development of safer vaccines.

Subunit vaccines have promising applications with the advantage of being safe, cost-effective, and efficacious. During the past two decades, various antigens have been extracted from Brucella, such as Omp19, Omp25, L7/L12, P39, SodC, InpB, AsnC, and TF (17-24). These available antigens have been shown to provide protection against Brucella infection by reducing the organ's bacterial load in mice. While such findings are highly promising, subunit vaccines using known antigens cannot provide the levels of protection conferred by live attenuated vaccines (25). Further investigation is needed to identify novel antigens, and increase vaccine efficacy. In contrast to the conventional vaccine development that requires cultivation and extensive empirical screening, reverse vaccinology (RV) is an interesting in silico approach to identify protective antigens using pathogen genomic data (26-29). RV has been implemented to identify protective antigens of numerous pathogens, including B. abortus (30-32).

The main goal of this study was to screen potential antigens in the genome of $B$. abortus using RV as a search strategy and subsequently evaluating the immunogenic capacity of the peptide in an animal model. We used an in silico methodology to select epitopes candidates based on their biological characteristics strongly associated with protective antigenicity from putative targets of small RNAs expressed in infected BMDMs. From these predictions, a transmembrane epitope of apolipoprotein $\mathrm{N}$-acyltransferase was selected for efficacy verification in a mouse model showing promising results to be used as an epitope-based vaccine against brucellosis that may induce robust immunity against the bacterium.

\section{MATERIAL AND METHODS}

\section{Ethics Statement}

This study was carried in strict accordance with the Brazilian laws 6638 and 9605 in Animal Experimentation. The protocol was approved by the Committee on the Ethics of Animal Experiments of the Federal University of Alfenas (CEUA $16 / 2020)$.

\section{Mice, Cell Culture and Bacteria}

The strain C57BL/6 mice aged 6-8 weeks were purchased from the Federal University of Minas Gerais animal facility (UFMG, Belo Horizonte, Brazil). Bone marrow cells were obtained from femora and tibia of mice and they were grown in bone marrowderived macrophages (BMDMs) as previously described by our group (33). B. abortus virulent strain 2308 was obtained from our own laboratory collection. They were grown in Brucella broth medium (BD Pharmingen, San Diego, CA, USA) for 3 days at $37^{\circ} \mathrm{C}$.

\section{BMDM Infection With $B$. abortus}

BMDMs were infected with virulent $B$. abortus strain 2308 at a multiplicity of infection of 100:1. Bacteria were centrifuged onto macrophages at $400 \times \mathrm{g}$ for $10 \mathrm{~min}$ at $4^{\circ} \mathrm{C}$ and then cells were incubated for $30 \mathrm{~min}$ at $37^{\circ} \mathrm{C}$ under $5 \% \mathrm{CO}_{2}$. Macrophages were extensively washed with HBSS to remove extracellular bacteria and incubated for an additional $90 \mathrm{~min}$ in medium supplemented with $100 \mu \mathrm{g} / \mathrm{mL}$ gentamycin to kill extracellular bacteria. Thereafter, the antibiotic concentration was decreased to $10 \mu \mathrm{g} / \mathrm{mL}$. Thirty minutes after infection, BMDMs were washed three times with HBSS before processing following homogenization with $100 \mu \mathrm{l}$ of LS TRIzol ${ }^{\circledR}$ reagent Invitrogen (Waltham, Massachusetts, EUA) for total RNA isolation.

\section{Small RNA Sequencing and Bioinformatics Identification}

The construction and sequencing of a strand-specific small RNA (15-50 nt) library was conducted by FASTERIS SA (Plan-lesOuates, Switzerland), based on the Illumina ${ }^{\circledR}$ TruSeq ${ }^{\circledR}$ Small RNA Library Prep Kit for Illumina HiSeq 2000 sequencing (Illumina Inc., San Diego, CA, USA). To remove adapter sequences from small RNA raw reads of sequencing, the Cutadapt tool was used (34) and sequencing quality was analyzed using the Trimmomatic V0.32 tool (35). Reads were mapped to the B. melitensis biovar Abortus (strain 2308) genome using the Bowtie program (36) to report the best alignment for each read allowing a maximum of one replacement per 
alignment. Using BedTool, reads mapped at alignment were analyzed to determine the depth of coverage across the genome determining the hotspots areas of small RNAs (37). Coverage with more than 50 reads and areas with a distance of less than $50 \mathrm{bp}$ were joined as the same hotspot area.

\section{Bioinformatic and Reverse Vaccinology}

To assess the putative targets of those small RNAs highly expressed by $B$. abortus during infection, one hundred coding genes were obtained using the intersect BedTool to indicate the overlap between small RNAs and coding genes (37). As the overlaps showed the possibility of affecting more than $50 \%$ of the $B$. abortus coding genes, which target genes contain the hottest hotspots (i.e., with the highest average coverage), by Watson-Crick base pairing complementarity was evaluated. The proteins from the putative target coding genes were filtered by assigning selection criteria according to biological characteristics: (1) subcellular location (SCL) using Psortb v3.0.2 program (38), (2) the presence of a signal peptide using SignalP 5.0 Server tool (39), and (3) the presence of transmembrane helices and exposed regions using three tools: TMPRED, SOSUI 1.11, and TMHMM 2.0 (40-42). The obtained proteins were then analyzed for biological function using an online tool UniProt Knowledgebase (UniProtKB) and only one of the 7 was selected (43). The selected protein apolipoprotein N-acyltransferase (WP_002965220.1) was used to identify epitopes composed of fifteen amino acids present in the extracellular portion of Int. The extracellular portion of the surface-associated target protein was subjected to the sequential mapping of epitopes predicted to bind tightly to major histocompatibility complex $(\mathrm{MCH})$ class II, using the tools NetMHCII 2.2, SYFPEITHI, and RANKPEP (44-46). To obtain the best candidates of putative immunogenic epitopes from Int, using Multalin 5.4, the obtained epitopes were aligned, and the linear amino acid sequence including approximately 15 amino acids that presented a repeats sequence was selected (47). For the epitope antigenicity test, the VaxiJen 2.0 server was used with the 0.5 and "probable antigen" cutoff (48). For the allergenicity test, the server "AlgPred: Prediction of Allergenic Proteins and Mapping of IgE Epitopes" was used with the hybrid method that consists of using the following five tools available on the server: SVMc, IgE, epitope, ARPs BLAST, and MAST (49). For the epitope similarity analysis, the Protein BLAST tool available on the NCBI platform was used (50). For the physical and chemical properties test, the ExPASy server ProtParam tool was used with a cutoff of 40 for structure stability values (51). The pipeline of bioinformatic analysis is depicted and summarized in Figure 1.

\section{Real-Time RT-PCR for Apolipoprotein $\mathrm{N}$-Acyltransferase Expression}

Thirty-minute B. abortus-infected BMDMs or the exponential growth of B. abortus in Brucella broth medium total RNA were extracted using TRIzol reagent (Invitrogen). Reversetranscription of $100 \mathrm{ng}$ from total RNA was performed using random primers according to the Illustra ${ }^{\mathrm{TM}}$ Ready-To-Go

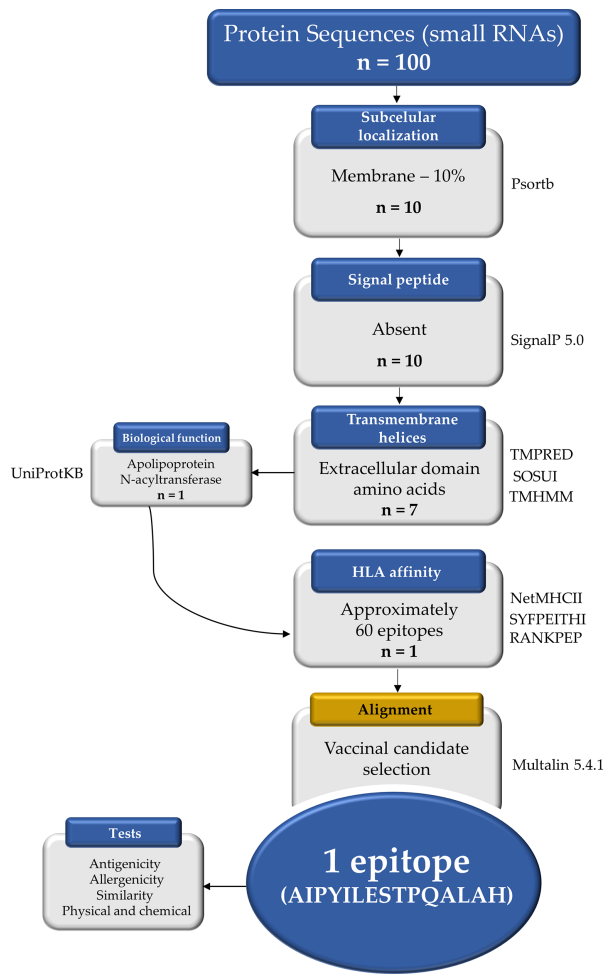

FIGURE 1 | Reverse vaccinology protocol workflow applied in this study to select a vaccinal epitope candidate. The one hundred protein sequences were obtained from the $\mathrm{NCBI}$ and ten proteins were localized in the plasma membrane by the Psortb tool. The TMPRED, SOSUI, and TMHMM tools identified 7 proteins with extracellular amino acid domain, but when analyzing the biological functions in the UniProtKB, only one was selected. Approximately 60 epitopes from the extracellular portion showed strong binding by HLAs according to the tools NetMHCII, SYFPEITHI, and RANKPEP. Using the Multalin tool the alignment was performed and the most promiscuous candidate among the epitopes was selected. n, number of proteins.

RT-PCR Beads kit (GE Healthcare, Buckinghamshire, UK). Real-time RT-PCR was conducted in a final volume of $10 \mu \mathrm{L}$ containing the following: SYBR ${ }^{\circledR}$ Green PCR Master Mix (Applied Biosystems, Foster City, CA, USA), with CDNA as the PCR template and primers to amplify specific fragments corresponding to specific gene targets: IntF: 5 ` - CTGA TGTGA T TGTCTGGCCG-3 ’, IntR: 5 ` CCTGAGGTGTCGATTCCAGT-3', Brucella 16S F: $5^{`}$ TCTCACGACACGAGCTGACG - ${ }^{\prime}$, Brucella $16 \mathrm{~S}$ R: $5^{`}$ - CCTGAGGTGTCGATTCCAGT -3`. The PCR reaction was performed using the ABI 7500 Real-Time PCR System (Applied Biosystems, Foster City, CA), with the following cycling parameters: $60^{\circ} \mathrm{C}$ for $10 \mathrm{~min}, 95^{\circ} \mathrm{C}$ for $10 \mathrm{~min}, 40$ cycles of $95^{\circ} \mathrm{C}$ for $15 \mathrm{sec}$ and $60^{\circ} \mathrm{C}$ for $1 \mathrm{~min}$, and a dissociation stage of $95^{\circ} \mathrm{C}$ for $15 \mathrm{sec}, 60^{\circ} \mathrm{C}$ for $1 \mathrm{~min}, 95^{\circ} \mathrm{C}$ for $15 \mathrm{sec}$, and $60^{\circ} \mathrm{C}$ for $15 \mathrm{sec}$. All data are presented as relative expression units after normalization to the Brucella 16S gene. PCR measurements were conducted in triplicate. The differences in the relative expression were analyzed by Student's $t$ test with a two-tailed distribution ( $\mathrm{p}<0.05$ indicates statistical significance). 


\section{Int Structural Modeling and Epitope-MHCII Docking}

The Int protein from Brucella was retrieved via the NCBI database, followed by molecular modeling by homology via WebServer Phyre $^{2}$, which uses the Markov model for the best possible global alignments to generate the most accurate protein in its main function (52). After modeling, the epitope under investigation from the protein was obtained, and the preparation was performed using the MGL tool, in which missing atoms were corrected and water molecules were removed (53). The same preparation was performed for MHCII molecules found on the PDB server (Protein Data Bank) (54). For docking execution, both files were converted to the PDBQT format required by AutoDock Vina (55), using the Openbabel tool (56). The gridbox was generated around the active sites of the recovered MHCII proteins. To visualize the interactions between epitope-MHCII in $2 \mathrm{D}$ and $3 \mathrm{D}$ diagram format, the Ligplot+, and Pymol tools were used, respectively $(57,58)$.

\section{Mice Experiments}

To assess the ability of vaccinal peptide to induce immune responses, 6-8-week-old C57BL/6 mice were contained in cages on a 12:12 light/dark cycle and fed ad libitum with standard rodent diet and no water restrictions. Mice were randomly separated into four treatment groups $(n=5)$ : (I) vaccinated and infected with $B$. abortus, (II) vaccinated and non-infected with B. abortus, (III) nonvaccinated and infected with $B$. abortus, (IV) non-vaccinated and non-infected with $B$. abortus and (V) Adjuvant and infected with $B$. abortus. Mice were immunized intraperitoneally (IP) with a prime and two boosts ( $0,7,14$ days) of vaccine formulation containing 10 $\mu \mathrm{g}$ of peptide in phosphate-buffered saline (PBS), combined with complete Freund's adjuvant (Sigma-Aldrich, St. Louis, MO, USA) at day 0 and incomplete Freund's adjuvant at days 7 and 14. Group $\mathrm{V}$ (adjuvant and infected) followed the same protocol receiving IP phosphate-buffered saline (PBS) combined with Freund's adjuvant (complete and incomplete). On day 21, mice were infected intraperitoneally with $B$. abortus S2308 virulent strain at a dose of $1 \times 10^{6} \mathrm{CFU} / \mathrm{animal}$ in $100 \mu \mathrm{L}$ PBS. Bacterial loads in the spleen, liver, and axillary lymph node from individual animals were homogenized in PBS, serially diluted 10-fold, and plated on Brucella broth agar (Difco, BD-Pharmingen, San Diego, CA). Plates were incubated at $37^{\circ} \mathrm{C}$, and the $\mathrm{CFU}$ were counted after 3 days as previously described (59). The experimental design is represented in Figure 2.

\section{Antibody Measurement From Serum Samples by ELISA}

To detect the immunogenicity of apolipoprotein $\mathrm{N}$-acyltransferase epitope, antigen-specific IgG, IgG1 and IgG2c in the immunized mice were tested by ELISA. Briefly, the immunoassay plates (Maxisorp, Nunc, Denmark) were coated with apolipoprotein Nacyltransferase epitope $(1 \mu \mathrm{g} / \mathrm{mL})$ diluted in $0.1 \mathrm{M}$ bicarbonate buffer ( $\mathrm{pH}$ 9.0) and incubated at $4^{\circ} \mathrm{C}$ overnight. The wells were washed three times with phosphate-buffered saline-Tween 20 (PBS$\mathrm{T}$ ) and then blocked with PBS containing $5 \%$ skimmed milk at $37^{\circ} \mathrm{C}$ for $1 \mathrm{~h}$. Vaccinated and non-vaccinated mice serum (1:10) was added to the well and incubated at room temperature for $2 \mathrm{~h}$. After adequate washing with PBS-T, plates were incubated with peroxidase-conjugated anti-mouse IgG (1:2500), IgG1 (1:5000), and IgG2c (1:20000) (Sigma Chemical Co., USA) for 1 h at $37^{\circ} \mathrm{C}$. After washing with PBS-T, substrate solution (0,5 mM TMB, 20 $\mathrm{mM} \mathrm{H} 2 \mathrm{O} 2$ no buffer PBS, pH 5) was added to each well, and plates were incubated in the dark at room temperature. Color development was stopped by adding $50 \mu \mathrm{L}$ of $2 \mathrm{M} \mathrm{H}_{2} \mathrm{SO}_{4}$ after 10 min. The absorbance value was measured using a microplate reader (Bio-Tropsch Tek Instruments, Winooski, Vt., USA) at a wavelength of $450 \mathrm{~nm}$. To confirm antigen-specificity, the serum from vaccinated and non-vaccinated mice was also used in immunoassay plates coated with the unrelated antigen lysozyme from hen egg white $(1 \mu \mathrm{g} / \mathrm{mL}$ ) (Sigma Aldrich) following the same parameters described above.

\section{Histopathology and Immunohistochemistry Assays}

The medial lobes of the mice liver were collected, fixed in $10 \%$ buffered formaldehyde solution, dehydrated, diaphanized, and embedded in paraffin. Four-micrometer-thick tissue sections were stained with hematoxylin and eosin (H\&E). Digital

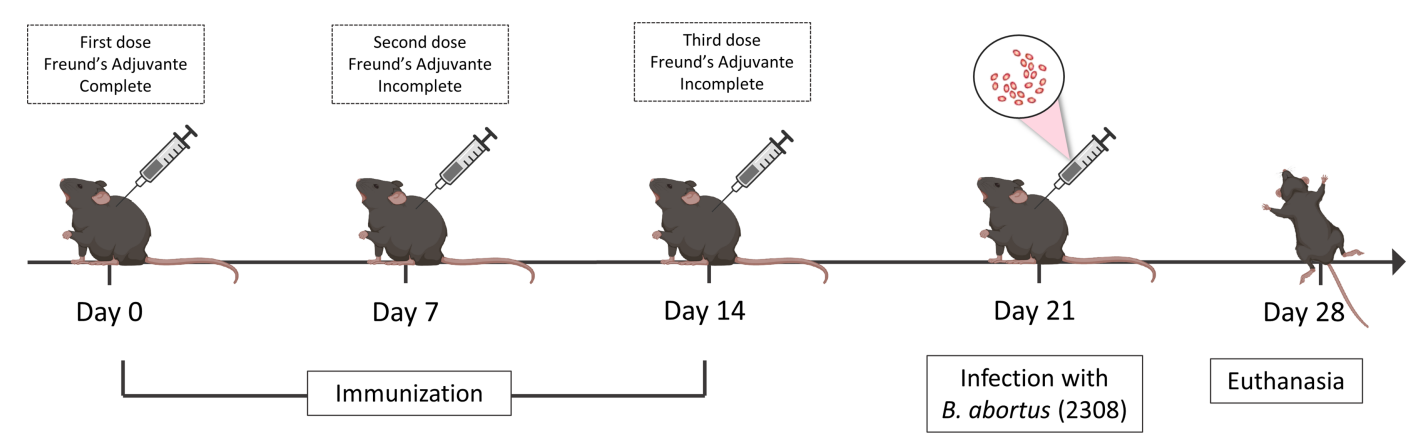

FIGURE 2 | Experimental design of in vivo analysis. C57BL/6 mice were vaccinated three times with intervals of seven days between doses, the first dose being in the presence of complete Freund's adjuvant and the other doses using the same incomplete adjuvant. Seven days after the last immunization the mice were challenged with the virulent strain 2308 of $B$. abortus and on day twenty-eight the animals were euthanized to obtain a spleen, liver and axillary lymph node. 
images were captured and digitized with the AxioVision LE software (Carl Zeiss, Oberkochen, Germany); all of the sample fields were photographed for histopathological evaluation. The histopathological changes were analyzed by Image Pro-PlusR 4.5 software (Media Cybernetics Inc., Silver Spring, MD, USA). The total number and size of granulomas present in histological liver sections was determined using an Axiophot microscope (Carl Zeiss, Oberkochen, Germany) with a 40x objective lens. Immunohistochemistry was performed as previously described (60). Briefly, liver sections were hydrated and incubated with $10 \%$ hydrogen peroxide in PBS for $30 \mathrm{~min}$. After being washed with PBS, slides were transferred to a humid chamber at room temperature, incubated with $25 \mathrm{mg} / \mathrm{ml}$ of skim milk for $45 \mathrm{~min}$, and then incubated with a primary antibody for $30 \mathrm{~min}$. For immunolabeling, diluted $(1: 5,000)$ serum from a rabbit experimentally inoculated with $B$. abortus S19 strain was used as polyclonal anti-B. abortus antibody. Then, tissue sections were washed with PBS, incubated with secondary antibody for $20 \mathrm{~min}$, washed again with PBS, and incubated for $20 \mathrm{~min}$ with streptavidin-peroxidase from a commercial kit (LSAB + kit; Dako Corporation, Carpinteria, CA). The reaction was revealed using $0.024 \%$ diaminobenzidine (DAB; Sigma), and sections were counterstained with Mayer's hematoxylin.

\section{Measurement of NO and IFN- $\gamma$ Into Splenocyte Culture Supernatants}

Spleens cells from C57BL/6 mice under treatment obtained after maceration were treated with ACK buffer $(0.15 \mathrm{M} \mathrm{NH} 4 \mathrm{Cl}$, $1.0 \mathrm{mM}$ KHCO3, $0.1 \mathrm{mM}$ Na2EDTA, $\mathrm{pH}$ 7.2) to lyse red blood cells. After that, the cells were washed with saline ( $\mathrm{NaCl} 0.8 \%$, wt/ vol) and suspended in RPMI 1640 (Gibco, Carlsbad, Calif) supplemented with $2 \mathrm{mM}$ L-Glutamine, $25 \mathrm{mM}$ HEPES, $10 \%$ (vol/vol) heat-inactivated FBS (Gibco, Carlsbad, Calif), penicillin G sodium $(100 \mathrm{U} / \mathrm{mL})$, and streptomycin sulfate $(100 \mu \mathrm{g} / \mathrm{mL})$. Spleen cells $\left(1 \times 10^{6}\right)$ were cultured in $200 \mu \mathrm{L}$ culture medium and incubated at $37^{\circ} \mathrm{C}$ with $5 \% \mathrm{CO}_{2}$. The supernatant of splenocyte cultures was collected after $24 \mathrm{~h}$ and nitric oxide (NO) measurement was performed according to the Griess method (61). The levels of IFN- $\gamma$ secreted were quantified from the supernatant of splenocytes cultures by antigen-capture ELISA. For this, $1 \times 10^{6}$ splenocytes (per well) were cultured in $200 \mu \mathrm{L}$ of culture medium in the absence and presence of 1 ug of the peptide as a stimulus for $72 \mathrm{~h}$ at $37^{\circ} \mathrm{C}$ with $5 \% \mathrm{CO}_{2}$. Aliquots from each well were then taken and IFN- $\gamma$ levels were measured using the Murine IFN- $\gamma$ Mini ABTS ELISA Development Kit (PeproTech Inc) following the manufacturer's instructions. Final cytokine concentrations were calculated using the standard curve for IFN- $\gamma$. The final reaction was measured using a microplate reader (Bio-Tropsch Tek Instruments, Winooski, Vt., USA) and read at $405 \mathrm{~nm}$ with wavelength correction set at $650 \mathrm{~nm}$.

\section{Analysis of Surface Markers CD86 and CD11b by Fluorescence Microscopic}

BMDMs $\left(1 \times 10^{6}\right.$ cells per well) were plated on imaging slides ( $\mu$-Slide 12-well, glass bottom, Ibidi GmbH, Munich, Germany), followed by stimulation with splenocytes supernatant for $48 \mathrm{~h}$. The cells were then washed three times with PBS and incubated with the anti-CD16/32 antibody (BD Biosciences, San Jose, CA) for 2 hours to block nonspecific bonds. The cells were then incubated with anti-CD86 and anti-CD11b, followed by staining with FITC-conjugated and PE-conjugated (BD Biosciences), respectively, overnight at $4^{\circ} \mathrm{C}$. The slides were washed with PBS and the nuclei were stained with $150 \mathrm{ng} / \mathrm{mL} 40,6$ diamino-2-phenylindole (DAPI; Thermo Scientific) for 1 hour. All images were captured using a Nikon Eclipse 80i fluorescence microscope (Melville, New York, U.S.A). Image J software was used to analyze the markings obtained for the nucleus (blue fluorescence), CD11b+ cells (green fluorescence), and CD86+ cells (red fluorescence).

\section{Real-Time RT-PCR for Pro and Anti- Inflammatory Cytokines Expression}

Liver and spleen macerate as well as BMDMs stimulated with splenocytes supernatant from the four experimental groups were homogenized with TRIzol reagent (Invitrogen) to isolate total RNA. Reverse-transcription of $1 \mu \mathrm{g}$ total RNA was performed using Illustra ${ }^{\mathrm{TM}}$ Ready-To-Go RT-PCR Beads (GE Healthcare, Buckinghamshire, UK). Real-time RT-PCR was conducted in a final volume of $10 \mu \mathrm{L}$ containing the following: SYBR ${ }^{\circledR}$ Green PCR Master Mix (Applied Biosystems, Foster City, CA, USA), with CDNA as the PCR template and primers to amplify specific fragments corresponding to specific gene targets: TNF- $\alpha$ F: 5'CATCTTCTCAAAATTCGAGTGACA-3', TNF- $\alpha$ R: 5'-TGGG AGTAGACAAGGTACAACCC-3'; IFN- $\gamma$ F: 5'-TCTGGAGG AACTGGCAAAG-3', IFN- $\gamma$ R: 5'-TTCAGACTTCAAAGAGT CTGAGG-3'; IL-6 F: 5'-CCAGGTAGCTATGGTACTCCA GAA-3', IL-6 R: 5'-GATGGATGCTACCAAACTGGA-3'; IL10 F: 5'-GGTTGCCAAGCCTTATCGGA-3', IL-10 R: 5'ACCTGCTCCACTGCCTTGCT-3'; TGF- $\beta$ F: 5'-TGACG TCACTGGAGTTGTACGG-3', TGF- $\beta$ R: 5'-GGTTCATGT CATGGATGGTGC-3'; iNOS F: 5'-CAGCTGGGCTGTACAA ACCTT-3', iNOS R: 5'-CATTGGAAGTGAAGCGTTTCG-3'. The PCR reaction was performed with ABI 7500 Real-Time PCR System (Applied Biosystems, Foster City, CA), using the following cycling parameters: $60^{\circ} \mathrm{C}$ for $10 \mathrm{~min}, 95^{\circ} \mathrm{C}$ for $10 \mathrm{~min}, 40$ cycles of $95^{\circ} \mathrm{C}$ for $15 \mathrm{sec}$ and $60^{\circ} \mathrm{C}$ for $1 \mathrm{~min}$, and a dissociation stage of $95^{\circ} \mathrm{C}$ for $15 \mathrm{sec}, 60^{\circ} \mathrm{C}$ for $1 \mathrm{~min}, 95^{\circ} \mathrm{C}$ for $15 \mathrm{sec}, 60^{\circ} \mathrm{C}$ for $15 \mathrm{sec}$. All data are presented as relative expression units after normalization to the $\beta$-actin gene (F: 5'-AGGTGTGCACTTTTTATTGGTCTCAA-3', R: 5'-TGTATGAAGGTTTGGTCTCCCT-3'). PCR measurements were conducted in triplicate. The differences in the relative expression were analyzed by analysis of variance (ANOVA) followed by Tukey's test ( $\mathrm{p}<0.05$ denotes statistical significance).

\section{Statistical Analysis}

Graphs were created and data analysis was performed using GraphPad Prism 8 software (San Diego, CA, USA), using oneway ANOVA or two-way ANOVA (Bonferroni post hoc test). Values $<0.05$ were considered statistically significant. 


\section{RESULTS}

\section{High-Throughput Sequencing Identifies the Expression of Small RNAs of B. abortus During Infection in Macrophages}

In the small RNA libraries from infected macrophages, we observed that $7.26 \%$ of all mapped sequences belonged to the B. abortus genome (Table 1). Knowing this, using the Bowtie software, it was seen that the small RNAs were found to be distributed in both chromosomes of the bacteria. By analyzing the depth of coverage of the sequences, we identified a total of 3954 regions of broad mapping of small RNAs in the genome of B. abortus, 2694 in chromosome I and 1260 in chromosome II. However, in local data of the bacterial genome, the presence of three peaks (hotspots) was observed, with two in chromosome I and one in chromosome II, constituted by small RNAs being mapped in the same position of the genome and large quantities (Supplementary Figure 1). With that, these three hotspots were selected, and we next concentrated our analysis on selecting the small RNAs that were mapped multiple times in these hotspots (Supplementary Figure 2). In total, we identified one hundred small RNAs with this characteristic which were then submitted to further analysis to detect the target mRNA in NCBI.

\section{Apolipoprotein $\mathrm{N}$-Acyltransferase (BAB1_2158) Is a Putative Target of $B$. abortus sRNAs and Its Expression Is Diminished During Earlier Time of BMDM Infection}

After the sequences were obtained from NCBI, the surfaceassociated proteins were selected by our SCL prediction tools. In this phase, 10 proteins were included, making up the final list of surface-associated proteins. The exposure of extracellular structures is an attraction for the immune system in the recognition of antigens and, therefore, the topology predictive tools selected seven proteins composed of extracellular domain amino acids. All selected extracellular portions were composed of at least 35 amino acids. To gain more insight into the biological functions of these 7 proteins, an analysis was performed to identify biological patterns associated with antigens. Of the 7 proteins analyzed, all were inferred by homology in UniProtKB, and a few are those reviewed regarding their biological function (Table 2). The information obtained by the Gene Ontology (GO) project showed that only two of these proteins would be involved in the biosynthesis process of the bacterial structure, yet one of them had a smaller number of exposed amino acids. The other, in addition to exposing 277 amino acids in the extracellular portion, also participates in the bacterial lipopolysaccharide biosynthesis process, becoming the target protein for further analyses. The other proteins analyzed had a transmembrane transport function, in addition to mediating cellular vesicle fusion processes.

Therefore, apolipoprotein N-acyltransferase (BAB1_2158) was selected for the further analysis of differential expression during BMDM infection. Knowing that small RNAs were expressed in large quantities by the bacterium during intracellular infection by Brucella, we investigated the levels of mRNA expression of Int in samples of intracellular and extracellular growth in a model of BMDM infection with $B$. abortus. The result of differential expression analysis showed that during BMDM infection, the bacteria decreased the Int gene expression when compared to an exponential extracellular growth model (Figure 3A). Taking into account the results of the in silico analysis, the negative expression of the Int coding gene may be related to an initial post-transcriptional gene regulation process used by the bacteria to repress the expression of this protein during intracellular infection, thus

TABLE 1 | Data obtained after mapping of reads.

\begin{tabular}{|c|c|c|c|c|}
\hline & $\begin{array}{c}\text { B. abortus infected } \\
\text { BMDMs }\end{array}$ & $\%$ & Control noninfectedBMDMs & $\%$ \\
\hline Processed Reads & 35.713 .113 & & 46.516 .010 & \\
\hline Reads mapped in the Mus musculus (GRCm38) genome & 33.120 .051 & $92.74 \%$ & 46.498 .741 & $99,96 \%$ of mapped reads \\
\hline
\end{tabular}

TABLE 2 | List of proteins predicted to have transmembrane helices and respective biological functions.

\begin{tabular}{|c|c|c|c|c|}
\hline $\begin{array}{l}\text { Protein ID } \\
\text { (NCBI) }\end{array}$ & $\begin{array}{l}\text { Length } \\
\text { (aa) }\end{array}$ & Single-line annotation (NCBI) & Biological function (UniProtKB) & Gene \\
\hline WP_002968965.1 & 386 & Lipase & $\begin{array}{l}\text { Pathogenesis and negative regulation of endosome organization, and vesicle } \\
\text { fusion }\end{array}$ & BAB2_0654 \\
\hline WP_002964284.1 & 270 & Phosphatidate cytidylyltransferase & CDP-diacylglycerol biosynthetic process & BAB1_1179 \\
\hline WP_002965220.1 & 532 & Apolipoprotein $\mathrm{N}$-acyltransferase & Lipoprotein biosynthetic process & BAB1_2158 \\
\hline WP_002971227.1 & 430 & $\begin{array}{l}\text { Xanthine/uracil/vitamin C permease } \\
\text { family }\end{array}$ & Transmembrane transporter activity & BAB2_0578 \\
\hline WP_002964796.1 & 400 & OPGC & Transmembrane transporter activity (sugar) & BAB1_1718 \\
\hline
\end{tabular}




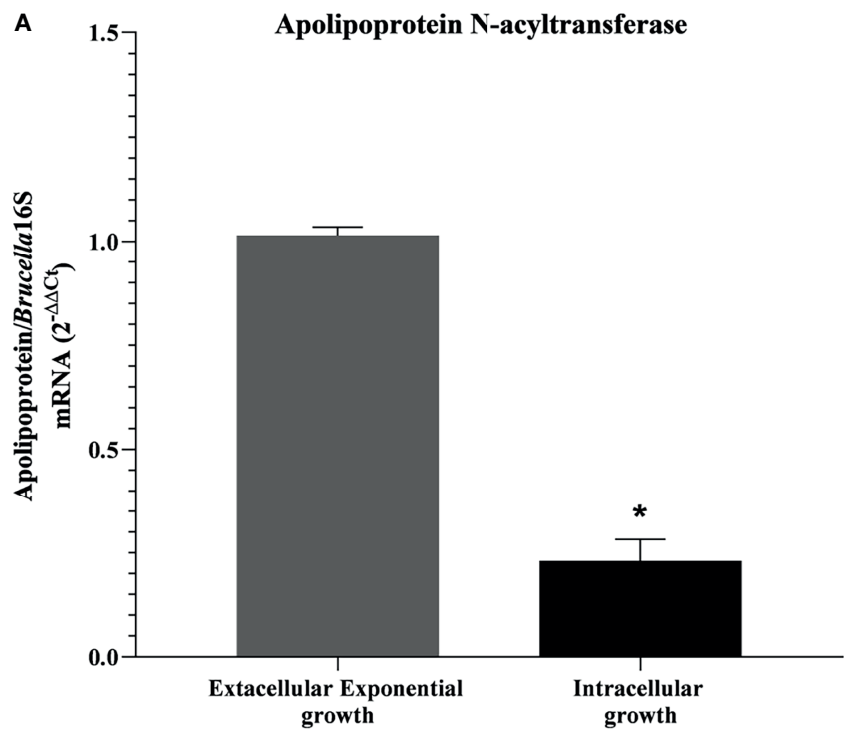

B

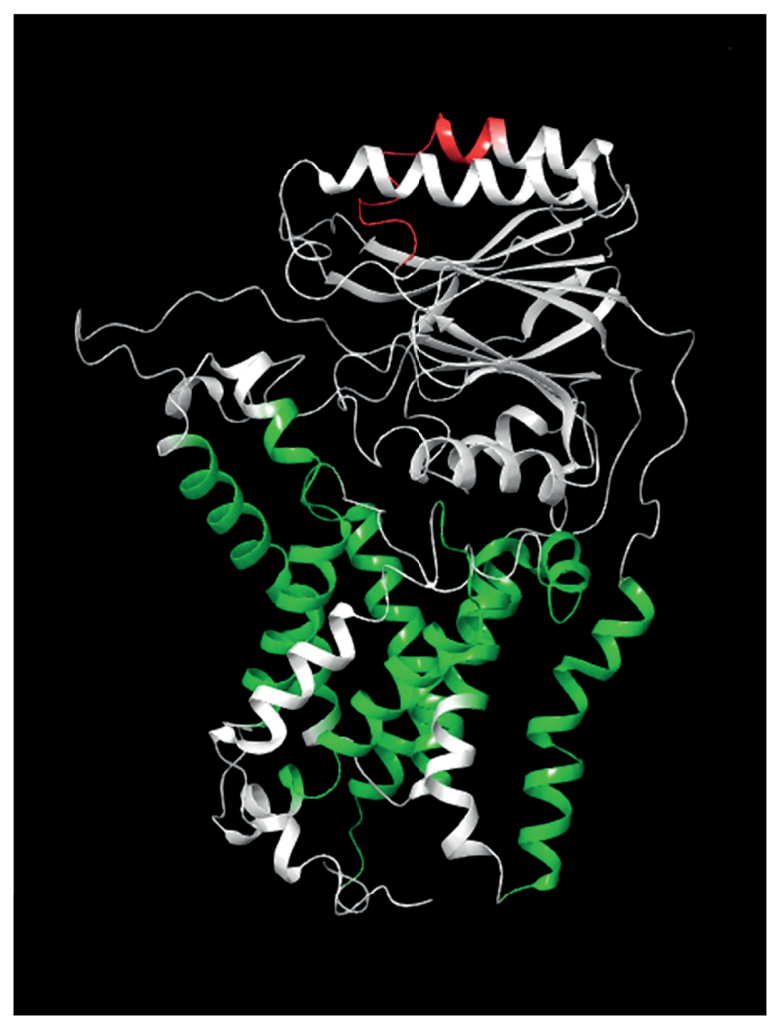

FIGURE 3 | Analysis of apolipoprotein N-acyltransferase target protein. (A) Decreased in the gene expression of apolipoprotein $\mathrm{N}$-acyltransferase is shown in an intracellular-growing model. Differential expression analysis of apolipoprotein $\mathrm{N}$-acyltransferase in model of extracellular and intracellular growth was measured by real-time RT-PCR and (B) position identification of selected epitope in 3D molecular modeled apolipoprotein N-acyltransferase by homology. Protein is represented in white; the selected epitope is highlighted in red, and the transmembrane helices are indicated in the models in green. Statistically significant differences relative to the extracellular exponential growth are represented by an asterisk $\left({ }^{*} P<0.05\right)$. 
establishing its replicative niche in the host cell. After reaching the replicative niche, $B$. abortus may increase the Int coding gene since it plays a crucial role in bacterial LPS biosynthesis during replication.

Since the results indicate a possible mechanism of gene expression control by the bacterium in stressful intracellular environments, we were searching for exposed immunogenic epitopes in the extracellular amino acid sequence of Int. The results obtained indicated approximately 60 epitopes that showed a strong binding affinity for HLA molecules (HLADRB1 0101, HLA-DRB1 0301, HLA-DRB1 0401, HLA-DRB1 0701, HLA-DRB1 1101, and HLA-DRB1 1501). In this stage, the predictor tools selected epitopes composed of exactly 15 amino acids. When subjected to alignment with the extracellular portion of the protein, the most promiscuous epitopes formed a conserved region; from this region, the epitope "AIPYILESTPQALAH" was selected. To identify the position of the selected putative immunogenic epitope in the Int, we performed molecular modeling, showing the selected epitope highlighted in red with transmembrane helices indicated in the model in green, as indicated in Figure 3B. When submitted to in silico screening tests, the epitope did not show the desired antigenicity (0.2800), however showed $100 \%$ similarity with sequences present only in the apolipoprotein $\mathrm{N}$-acyltransferase of $B$. abortus. To increase the confidence of using the selected epitope in future in vitro and in vivo evaluations, allergenicity was tested using the AlgPred software, characterizing it as nonallergenic. Although when analyzing the physicochemical properties, the epitope was shown to be unstable (40.27), since it did not reach the minimum cut-off value for stability, it had a relatively good half-life in mammalian cells (Half-life reticulocytes: 4.4h; Half-life yeast: $>20 \mathrm{~h}$; Half-life E. coli: $>10 \mathrm{~h}$ ), that is, despite its instability in the medium, it is suggestive that when it binds to the MHCII cleft, it can present the desired stability.

\section{Molecular Docking Between the Selected Putative Immunogenic Epitope From Int and MHC-II Shows High Probabilities of Interaction Between Them}

Although not all structures of MHC-II were found in the database (IEDB), we used the structure of 3 available proteins: HLA-DRB1:0101 (PDB: 5NI9), HLA-DRB1:0401 (PDB: 5V4M) and HLA-DRB1:1501 (PDB: 5V4N). When performing the molecular docking of the "AIPYILESTPQALAH" epitope, the results showed great interaction energy of all alleles based on the AutoDock Vina software (Table 3). To represent the molecular docking between the epitope and the MHC-II allele, we chose the interaction with the highest interaction power pointed out by the software. The epitope in question interacted very well with the MHCII of the HLA-DRB1:0101 allele, having the best interaction values, with an energy of $-8.1 \mathrm{Kcal}^{\mathrm{mol}}{ }^{-1}$ and presenting a total of 9 hydrogen bonds between the epitope and the MHC, with two bonds involving the amino acid HIS259 of the MHC with the amino acids LEU303 at a distance of $3.09 \AA$ and with the amino acid ALA304 at a distance of $3.26 \AA$ from the epitope. One link of amino acid ASN260 of MHC with amino acid HIS305 was $3.21 \AA$ from the epitope, one link of amino acid GLN242 of MHC with amino acid PRO293 showed a distance of $3.09 \AA$ from the epitope, two linkages involving amino acid TYR238 of MHC with the amino acid ILE292 was $2.91 \AA$ away and the link with the amino acid ALA291 was at a distance of $3.00 \AA$ from the epitope; also, a link of the amino acid LYS249 of the MHC with the amino acid GLU297 was at a distance of $3.06 \AA$ and finally two bonds involving amino acids TYR208 and HIS191 of the MHC, showed distances of $2.90 \AA$ and $3.24 \AA$, respectively, with amino acid SER298 of the epitope (Figures 4A, B). In summary, the peptide was shown to have a great ability to interact with MHC-II slits, especially with the HLA-DRB1:0101 allele, showing excellent interaction with 9 of the 15 amino acids of the epitope. Although minor binding strengths have been identified, this does not preclude the possibility of interaction between peptide-alleles.

\section{Immunization of Mice With Epitope-Based Vaccine Induces Protection Against B. abortus Infection and Specific Humoral and Cell Immune Responses Against the Epitope From Int}

After immunization, vaccinated and unvaccinated mice were challenged by intraperitoneal infection with $B$. abortus; after seven days, organs were collected to determine bacterial loads. In the spleen, liver and axillary lymph node of mice vaccinated with the peptide, fewer viable bacteria were recovered when compared to the control group (Figure 5A).

To evaluate the potential use of the epitope-based vaccine, the protection level induced in mice against virulent challenge infection was assessed. The degree of vaccine efficacy in C57BL/6 mice was determined by subtracting the mean CFU/ organ recovered from mice after vaccination and challenged from the mean CFU/organ recovered from non-vaccinated but challenged control mice. At this time, it was seen that the presence of vaccinal peptide in the animal organism triggered a higher degree of protection against infection, approximately 1.20/0.80/0.84-log in spleen, liver, and axillary lymph node, respectively (Table 4). Finally, aiming to exclude the bias of adjuvant composing the vaccine solution, the group that received only adjuvant was evaluated. The result showed $6.12 \pm 0.36$, $5.73 \pm 0.09$, and $5.73 \pm 0.12$ for spleen, liver, and lymph node, respectively, where there was no statistically significant difference compared to the unvaccinated group. Ours results showed that the RV-selected epitope provided significant protection to C57BL/6 mice against B. abortus.

To verify the peptide potential to induce a specific humoral immune response in immunized mice, the levels of specific IgG, IgG1, and IgG2c antibodies were measured by ELISA in mice serum. The immunoglobulins in immunized mice with peptide vaccine were significantly higher than those of the nonvaccinated group (Figure 5B). It was not observed reaction to unrelated antigen lysozyme from hen egg white. In addition, the amount of IFN- $\gamma$ showed significantly increased in splenocytes from vaccinated mice stimulated with peptide when compared to 
TABLE 3 | Molecular docking results according to AutoDock Vina software.

MHC-II Connection Power (Kcal.mol-1) Hbonds Non-ligand residues involved in hydrophobic Non-ligand residues involved in hydrophobic contacts MHC contacts epitope

\begin{tabular}{llccc}
\hline 5N19 & $-8,1$ & 9 & 11 & 5 \\
5V4M & $-6,6$ & 5 & 8 & 6 \\
5V4N & $-7,1$ & 7 & 10 & 3
\end{tabular}

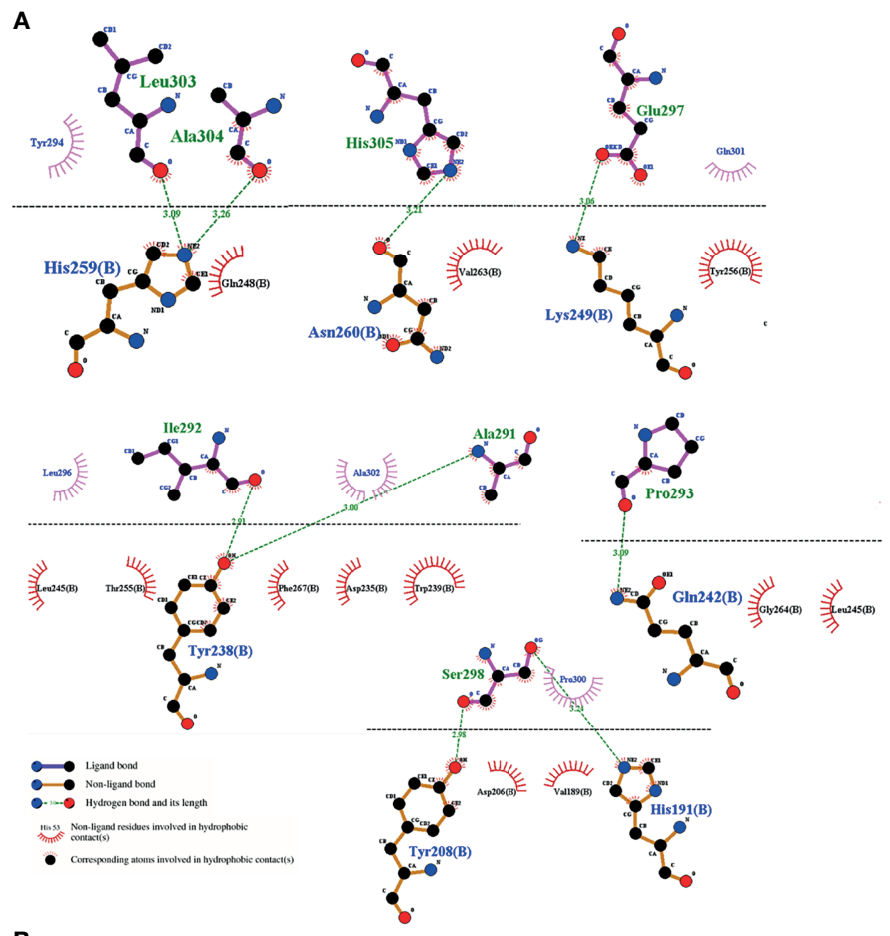

B

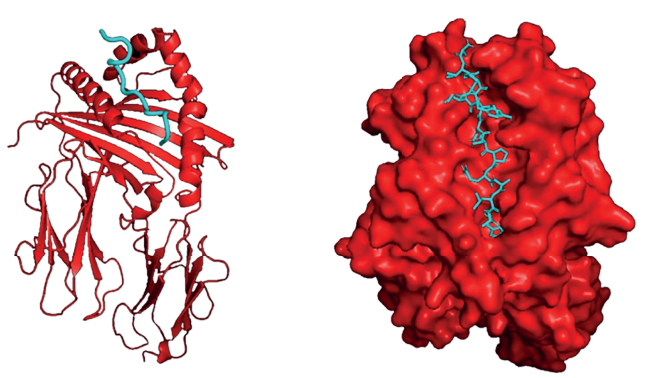

FIGURE 4 | Interaction between the selected epitope from apolipoprotein N-acyltransferase and MHC-II allele. (A) 2D diagram of the best interaction between the HLADRB1:0101 allele and the epitope, representing above the dotted line epitope amino acids and below line MHCIl amino acids and (B) 3D diagram of the interactions.

splenocytes from non-vaccinated mice, or when compared to non-stimulated cells (Figure 5C), indicating the specificity of the immune response of immunized mice not only in humoral but also in cellular response.

\section{Unvaccinated Mice Showed Greater Liver Damage When Infected With $B$. abortus}

B. abortus infection is associated with the formation of focal granulomatous lesions in the spleen, liver, and lymphoid tissues of both humans and rodents, starting 1-2 weeks post-infection (62). To determine the characteristics of liver pathology upon vaccination with peptide during $B$. abortus infection, we performed the histopathological analysis of liver tissue from vaccinated and unvaccinated C57BL/6 mice and, challenged with $B$. abortus. Infection with $B$. abortus resulted in the formation of hepatic granulomas in both groups (Figures 6A, C). In morphometric analysis, a greater number of granulomas was observed in the tissue of animals that were not vaccinated with the peptide and challenged by bacteria compared to the 

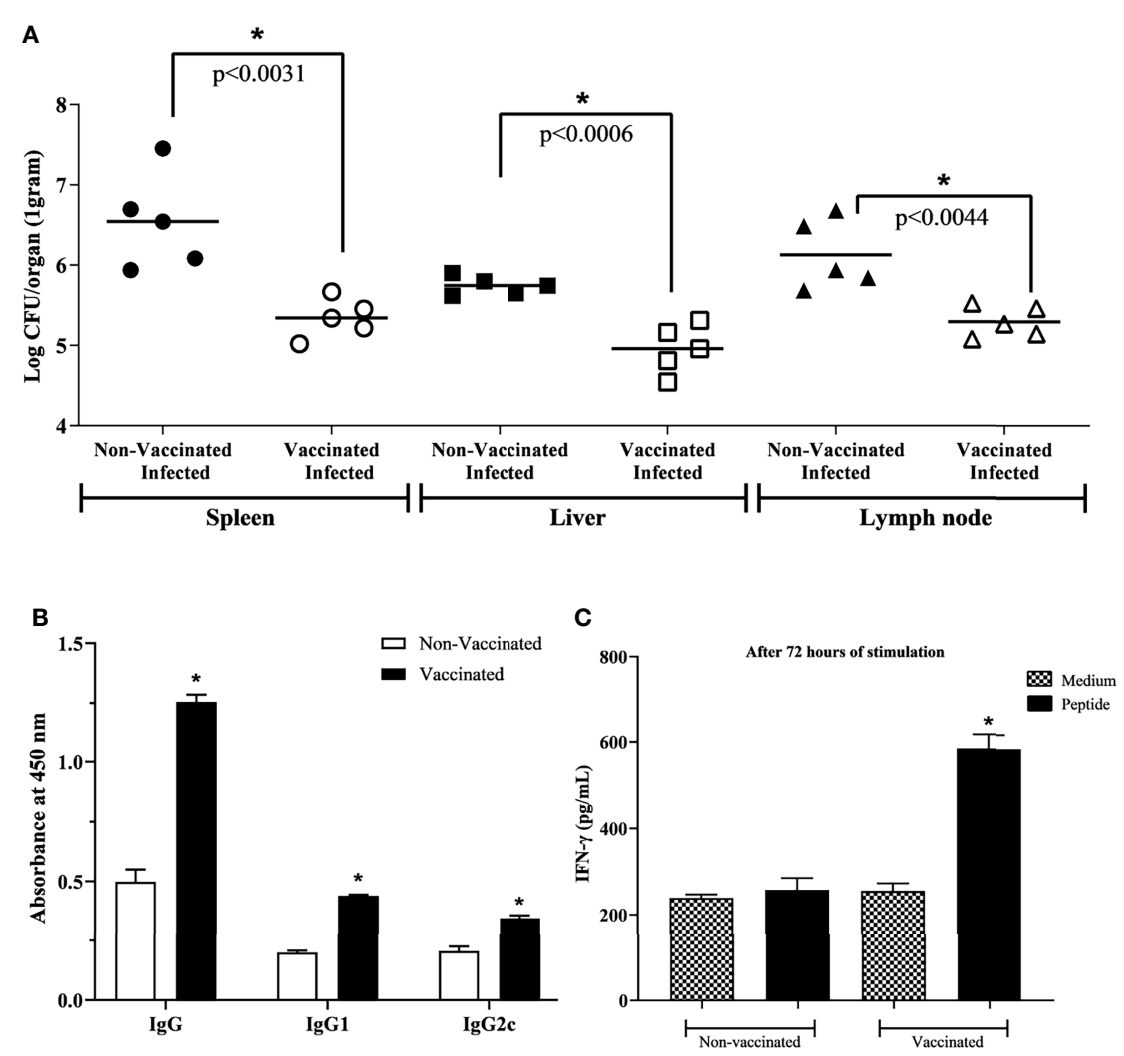

FIGURE 5 Protective efficacy and specificity after three rounds of immunization. (A) For protection evaluation, vaccinated mice were challenged with $1 \times 10^{6}$ CFU/ bacteria. One-week post-challenge, organs were collected to determine bacterial loads to assess protection efficacy. A smaller number of viable bacteria was identified in vaccinated mice, indicating great protection efficacy. (B) Specific IgG, IgG1, and IgG2c antibodies in the immunized and non-vaccinated mice serum. (C) IFN- $\gamma$ production by vaccinated or non-vaccinated mice splenocytes stimulated or non-stimulated with selected peptide. Data points were individual values of CFU determinations $(n=5)$ and analyzed using a student's t test. ${ }^{\star} P<0.05$ relative to the non-vaccinated and infected group.

TABLE 4 | Protective efficacy conferred by vaccinal peptide against $B$. abortus infection.

\begin{tabular}{|c|c|c|c|c|c|c|}
\hline Group $(n=5)$ & $\log _{10}$ CFU (Spleen) ${ }^{a}$ & Log Protection & $\log _{10}$ CFU (Liver) & Log Protection & $\log _{10}$ CFU (Lymph node) & Log Protection \\
\hline Vaccinated & $5.34 \pm 0.28^{\star}$ & 1.20 & $4.96 \pm 0.34^{*}$ & 0.80 & $5.30 \pm 0.19^{\star}$ & 0.84 \\
\hline Non-vaccinated & $6.54 \pm 0.63$ & - & $5.74 \pm 0.13$ & - & $6.13 \pm 0.43$ & - \\
\hline
\end{tabular}

Protection units of vaccinated group are compared with that of non-vaccinated with Student's t-test, ${ }^{*} P<0.05$ is statistically significant.

${ }^{a} \mathrm{CFU}$, colony-forming units.

vaccinated group (Figure 6G). The same result was seen when analyzing the area, which was greater in granulomas from unvaccinated animals (Figure $\mathbf{6 H}$ ). Histopathological lesions during Brucella infection usually are associated with the bacterial load. To determine the relationship between granuloma formation and the bacteria present in the granuloma, we performed immunohistochemistry to immunolabel $B$. abortus. Figures 6E, $\mathbf{F}$ showed the presence of B. abortus in the granulomatous lesions presented in the liver of vaccinated and infected mice and non-vaccinated and infected mice, respectively. The detection of intralesional bacteria confirms that the inflammatory lesions described in this study are due to systemic $B$. abortus infection. No observable lesions were found in tissues from uninfected mice (Figures 6B, D).

\section{Vaccination Induces Positive Expression of Pro- and Anti-Inflammatory Cytokines in Animals Infected With B. abortus}

The liver is the most commonly affected organ in patients with active brucellosis (63), which is why liver macerates from the four experimental groups were collected for evaluation of the expression of the anti-inflammatory genes $I L-10$ and TGF- $\beta$. In the differential expression analysis, an increase in these cytokines was observed in vaccinated and infected $\mathrm{C} 57 \mathrm{BL} / 6$ mice when compared to the other groups (Figures 7A, B). Therefore, the reduction in liver pathology can be attributed to a decrease in the number of viable bacteria and an increase in anti-inflammatory cytokines, resulting in a consequent reduction in liver damage. Concomitantly, the splenic tissue was evaluated and the results obtained showed that all groups, 


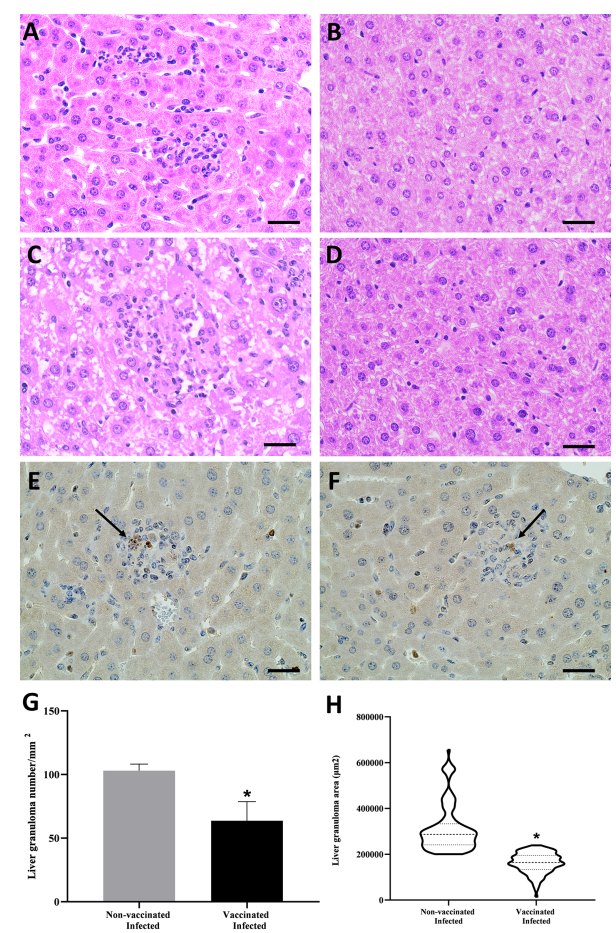

FIGURE 6 | Histopathology analysis, immunohistochemistry, and morphometric of hepatic tissue of B. abortus infected C57BL/6 mice. (A) Representative of hematoxylin- and-eosin-stained sections of hepatic tissue from mice vaccinated and infected, (B) vaccinated and non-infected, (B) unvaccinated and infected, and (D) non-vaccinated and non-infected. Immunohistochemistry sections of hepatic tissue from mice vaccinated and infected (E) and non-vaccinated and infected (F) mice containing the $B$. abortus inside the granuloma. The graphs analyze the granulomas of liver tissue sessions that were sequentially captured in terms of number (G) and area $\mathbf{( H )}$. Statistically significant differences relative to the non-vaccinated group are represented by an asterisk $\left({ }^{*} P<0.05\right)$. The arrows indicate the $B$. abortus within the granuloma. Scale bars: $50 \mu \mathrm{m}$.

except for the control, showed upregulation of the proinflammatory cytokine-coding genes INF- $\gamma, T N F-\alpha$, and $I L-6$, which are characteristic of inflammation (Figures 7C-E), but the vaccinated and infected group stood out due to the increased expression when compared to other groups. Likewise, it was seen that IL-10 (Figure 7E) is up-regulated in this group, suggesting that vaccination induces an attempt to control the inflammatory process generated by systemic infection with $B$. abortus.

\section{BMDM's From C57BL/6 Mice Stimulated With Supernatant Splenocytes From the Vaccinated and Infected Group Showed Higher Expression of CD86}

In vivo analysis results indicate the activation of an adaptive immune response. Knowing this, we tried to understand the mechanisms by which a more efficient immune response activation process against the bacteria occurs. BMDMs were evaluated for the expression of co-stimulatory molecules after being stimulated with the splenocyte supernatant. The results obtained by fluorescence microscopy show that BMDMs stimulated with the supernatant from the spleen of vaccinated and infected animals were more activated, due to intense CD86 labeling (Figure 8A), and that they even expressed a higher level of $i N O S$ expression, the gene that stimulates NO production
(Figure 8B). To confirm this result, the measurement of NO was performed in the in the supernatant of these macrophages. The results obtained showed the greater production of NO by BMDMs that were more activated (Figure 8C), which may reveal an increased phagocytic and microbicide capacity to eliminate the bacteria.

\section{DISCUSSION}

The development of subunit vaccines to protect against brucellosis is crucial to avoid the disadvantages of the used live attenuated vaccines RB51 and S19 against $B$. abortus $(64,65)$. New vaccines will be designed according to immune responses during a natural infection in animal models and the identification of intracellular and cell surface immunodominant components of Brucella spp (66-69). Using RV, it has been shown that the genome of $B$. abortus contains approximately 80 genes encoding putative lipoproteins that have diverse functionalities, including pathogenic processes $(70,71)$. Knowing this, recent studies have shown that some bacterial cell surface proteins can provide significant protection against Brucella, such as L7/L12 (72), Omp19, Omp31 (73), BP26 (74), and Omp25 (75, 76), which have been shown to be immunodominant antigens that stimulate 
A

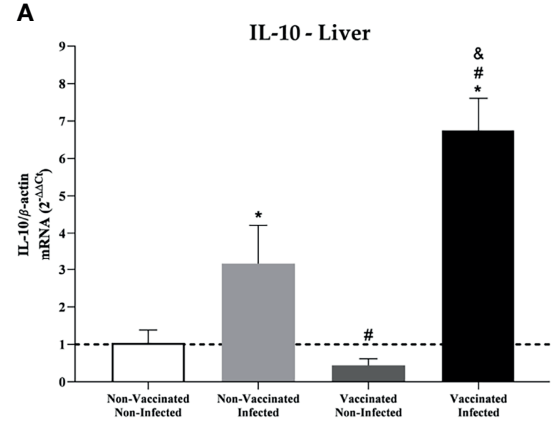

C
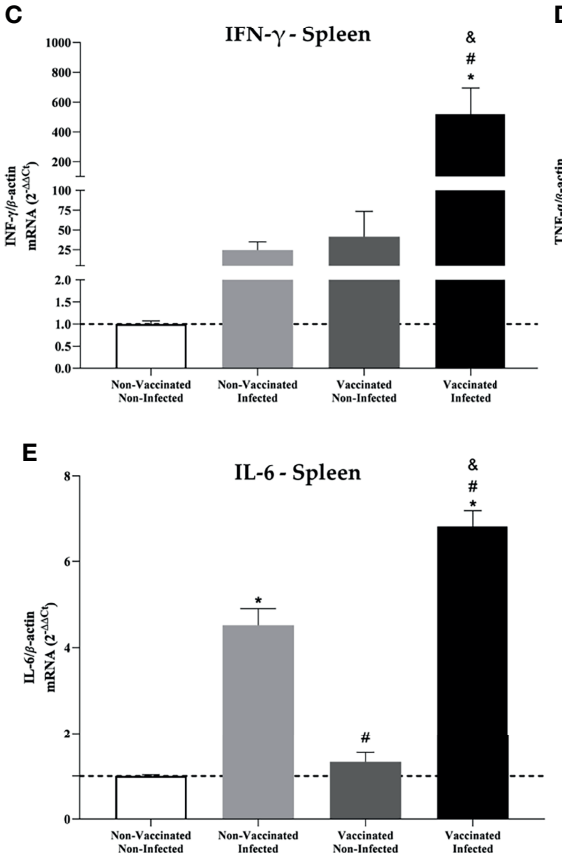

B

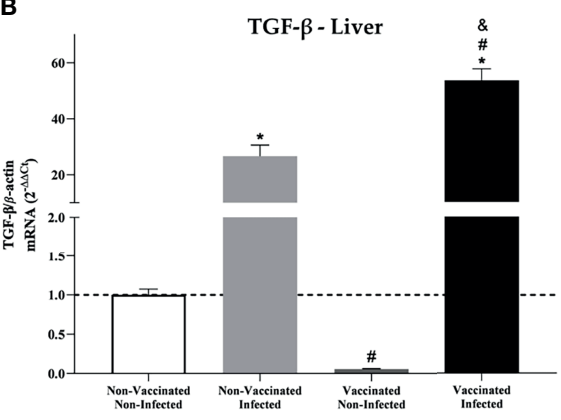

D

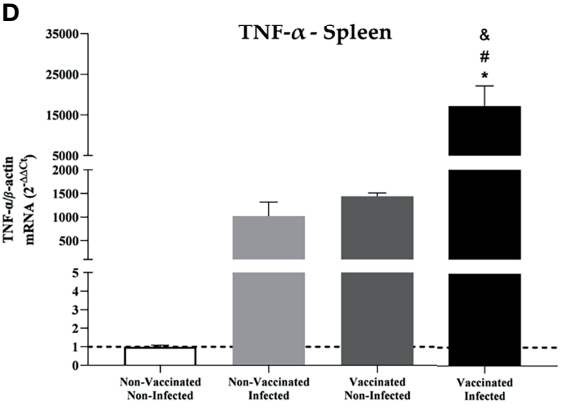

$\mathbf{F}$

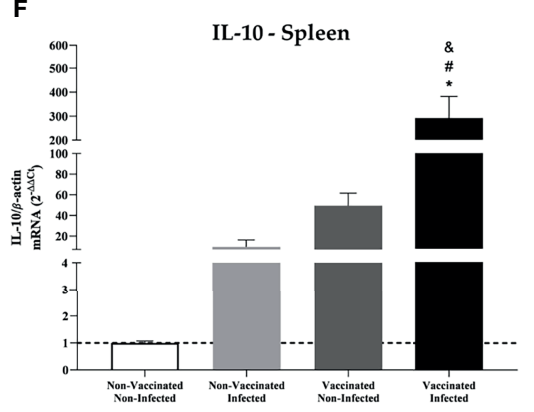

FIGURE 7 | Liver and spleen showed increased expression of pro and anti-inflammatory cytokine in mice vaccinated and infected with B. abortus. Differential expression analysis of (A) IL-10 and (B) TGF- $\beta$ from the liver tissue and (C) IFN- $\gamma$, (D) TNF- $\alpha$, (E) IL-6, and (F) IL-10 from the spleen of C57BL/6 mice from the four experimental groups evaluated in this study. Transcript levels were measured by real-time RT-PCR. Error bars represent the mean \pm SD of samples assayed in triplicate. ${ }^{\star} P<0.05$ relative to the non-vaccinated and non-infected group. ${ }^{\#} P<0.05$ relative to the non-vaccinated and infected group. ${ }^{\&} P<0.05$ relative to the vaccinated and non-infected group.

host immunity and trigger a protective response against infection in a mouse model. Bacteria of the genus Brucella can live, replicate and persist within phagocytes using their mechanisms to evade the immune system and establish their replicative niche within the host cell (77). In this context, previous studies suggest that small RNAs may be directly related to the timely gene expression of virulence factors in a variety of pathogenic bacteria such as Listeria and Yersinia $(78,79)$. Considering that the expression of small bacterial RNAs allows changes in the host cell phenotype, and knowing that these small RNAs act on gene activation and repression, we evaluated the capacity that a rationally predicted epitope of Int, a target protein of small RNAs expressed on large scale by the bacteria during macrophage infection, would have to activate protective immune responses during infection by $B$. abortus in a murine model.
Since Brucella species are equipped with a variety of wellorganized immune evasion strategies to establish chronic infections, including the use of small non-coding RNAs (80, 81), we performed a detailed analysis from data from the sequencing of small RNAs expressed during the infection of BMDMs with B. abortus, showing that $7.26 \%$ of the small RNAs were mapped in the bacterial genome. This was consistent with previous reports that identified expression levels of similar small $B$. abortus RNAs during the infection of murine macrophages (82). Casewell et al. reported that B. abortus small RNAs, abcR1 and abcR2 play essential roles in pathogenicity and chronic infection, resulting in a significant decrease in intracellular survival in a mouse model and in macrophages (83). Another group identified 129 small RNAs of Brucella that play significant roles in diverse biological processes, ranging from physiology to 
A

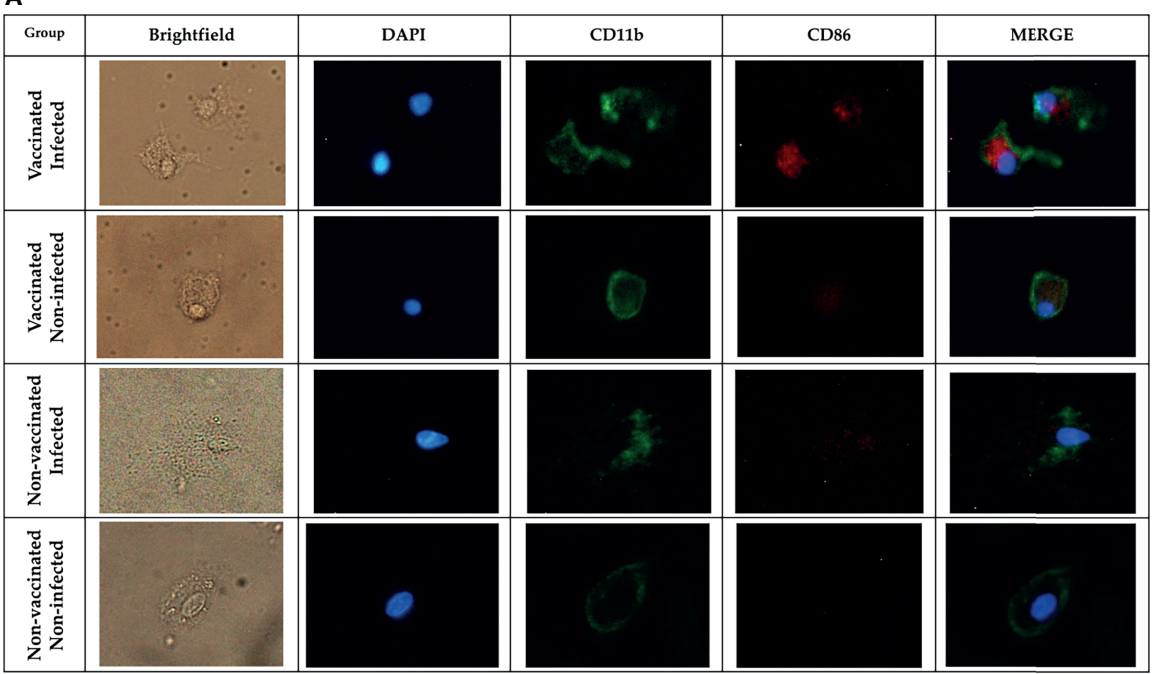

B

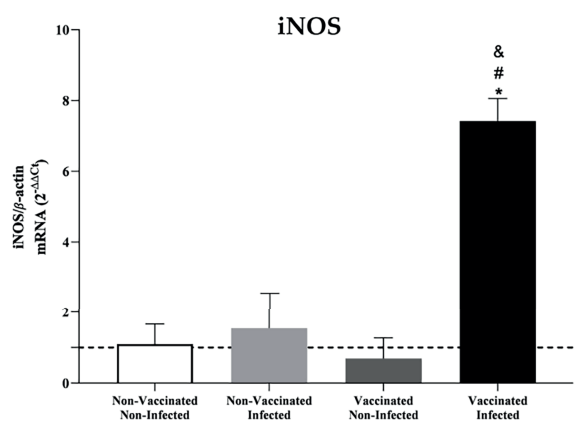

C

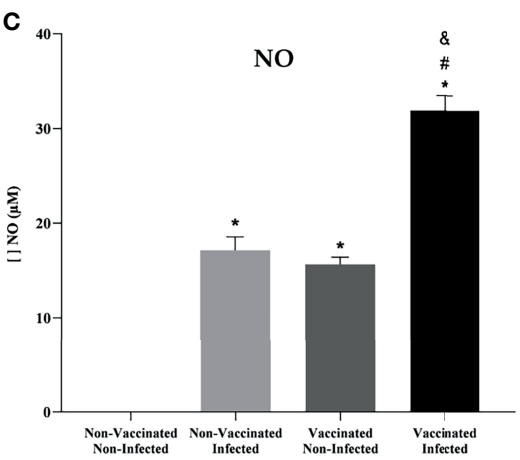

FIGURE 8 | In-vitro analysis showed an increased phagocytic and microbicide capacity in BMDM's. (A) Fluorescence microscopy shows activation of BMDM's by the CD86 molecule after being stimulated with supernatant from the spleen of C57BL/6 animals. (B) Differential expression analysis of iNOS in stimulated BMDM's was measured by real-time RT-PCR and (C) NO dosage using Griess method. Error bars represent the mean \pm SD of samples assayed in triplicate. ${ }^{\star} P<0.05$ relative to the non-vaccinated and non-infected group. ${ }^{\#} P<0.05$ relative to the non-vaccinated and infected group. ${ }^{\&} P<0.05$ relative to the vaccinated and noninfected group. Scale bars: $20 \mu \mathrm{m}$.

virulence, as well as in host-pathogen interaction (84). These reports shed light on the importance of small non-coding RNAs in Brucella immunity, pathogenesis, and intracellular survival, modulating the host's immune response. Here, we selected a non-allergenic with a good half-life in mammals, yeast, or E. coli, from a putative target of a more highly expressed Brucella sRNA. Rationally, we also take account of the structural and functional aspects of this target meeting the epitope "AIPYILESTPQALAH" of apolipoprotein $\mathrm{N}$-acyltransferase (Int), even it presented low immunogenicity in silico. Although other proteins were predicted as possible targets of Brucella sRNA in our analyses, this one, in particular, stood out due to its biological function and strong epitope MHCII-interact capacity. Reportedly, Int functionally constitutes Brucella's outer membrane and plays a crucial role in bacterial LPS biosynthesis $(70,71,85)$. Interestingly, one of the main virulence factors of Brucella identified so far is its non-canonical LPS $(86,87)$ which exhibits favorable properties for the bacterium, including low endotoxicity, high resistance to degradation in macrophages, and protection against immune responses (88-90). The differential expression analysis of this protein-coding gene was performed in intracellular growth samples in a BMDM model infected with $B$. abortus, showing a drastic reduction in expression, corroborating our hypothesis that there is a post-transcriptional gene regulation process used by the bacterium to repress the expression of Int during the early time of infection. This regulation can favor the bacteria permanence and replication in the host cell and, after reaching its niche replication, increase the expression of genes related to LPS biosynthesis as apolipoprotein $\mathrm{N}$-acyltransferase. Therefore, in this study, in an unprecedented way, we evaluated the capacity of a specific Int epitope selected by RV to induce an immune response in a murine model infected with $B$. abortus. The candidate epitopebased vaccine was able to trigger protective immune responses, when the amount of viable $B$. abortus in the liver, spleen, and axillary lymph nodes of vaccinated and unvaccinated mice when challenged intraperitoneally by this pathogenic bacterium was evaluated. It was observed that immunization considerably 
decreased the recovery of $B$. abortus in the tissues evaluated and induced mean systemic protection of 0.94 logs when compared to unvaccinated animals. Other evaluated Brucella antigens behaved similarly; for example, the recombinant Omp16 and Omp19 and the encapsulated recombinant liposome Omp25 induced protection comparable to S19 in vaccinated mice after challenge $(17,18,91)$. In addition, the Omp28 subunit vaccine increased resistance against the $B$. abortus challenge by inducing a CD4+ Th1 response, that protects against infection, but at a lower level than live attenuated vaccines (92). Other studies, analyzing the level of splenic CFU, showed levels of protection in animals immunized with S19 ranging from 1.4 to $2.9 \log (93,94)$. Corroborating our results, these findings in the literature reinforce good protection obtained in our study when compared to S19, which is a vaccine strain constituted by the bacterium in its entirety. We also found that the levels of IgG, IgG1and IgG2c in serum of vaccinated mice were higher than those in the non-vaccinated control group. Specific antibodies have been used as important indicators for evaluating vaccine candidates (95). In a particular study, rBLSOmp31 was synthesized and found the protein could induce IgG responses against Brucella in the immunized mice (96), as also demonstrated the humoral specificity in immunized mice with the Brucella Omp2b protein (97). In this study, we found that an epitope from apolipoprotein $\mathrm{N}$-acyltransferase could also induce the humoral immune response in mice.

The characteristic pathological manifestation of B. abortus infection is granulomatous inflammation associated with bacterial load (98). In this study, we detected a significant reduction in the number and size of granulomas in the livers of animals vaccinated with the peptide compared to unvaccinated animals, suggesting that the vaccination induced an effective inflammatory immune response in this tissue. This condition is well defined, whereas, as infection in mice infected with Brucella progresses, the granulomas progressively decrease in size and number after 2-3 weeks of infection (62). In parallel, we saw that the reduction of pathology in vaccinated mice was accompanied by an increase in the expression of $I L-10$ and TGF$\beta$ in the liver of infected animals. Although the impact of IL-10 on Brucella persistence and the establishment of chronic infection through macrophage modulation has been previously demonstrated using IL-10-deficient mice $(99,100)$, our findings provide evidence that the increased expression of $I L-10$ is related to an immunoregulatory mechanism dampening excessive Th1 responses (101). In this context, it is noted that the absence of IL10 results in severe pathological changes in different bacterial infections $(102,103)$. Here, we can speculate that the reduction in liver pathology in immunized and infected animals may have been mediated by an increase in anti-inflammatory cytokines, and attributed to a previous reduction in the number of viable bacteria.

Cell-mediated immunity is considered critical for the protective immune response against facultative intracellular pathogens $(104,105)$. Our results showed that the Int epitope induced the enhanced production of TNF- $\alpha$ and IFN- $\gamma$ in spleen cells, suggesting that there is some induction of a Th1-type immune response by the vaccine peptide. In particular, IFN- $\gamma$ is essential for immune protection against Brucella infection that induces more polarization toward Th1 cells $(106,107)$. In addition, functional TNF- $\alpha$ has been shown to link the proinflammatory response and adaptative immune response in Brucella-infected mice (108). High levels of IL-6 were produced by the splenocytes of immunized and infected mice. It was recently shown that IL- 6 is required for the induction of IFN- $\gamma$ and TNF- $\alpha$ by infected splenocytes, in addition to promoting the differentiation of CD8+ T cells, indicating a protective role for IL-6 against $B$. abortus that parallels the type of Th1 immunity response $(109,110)$. Similarly, significant levels of IL-10 in immunized mice were also detected in spleen cells. These results are consistent with the scenario seen in liver tissue, suggesting that an inflammatory immune response has already occurred to the point of generating an anti-inflammatory response with infection control characteristics. In this context, the balance between the production of pro- and antiinflammatory cytokines appears to be crucial for the host's ability to eradicate the infection (100).

Since immunization triggered an effective adaptive immune response in vivo, the activation of BMDMs when stimulated with supernatant from splenocytes from treated animals was evaluated in vitro. It was observed that the supernatant from vaccinated and infected animals secreted cellular components capable of stimulating macrophages more intensely in the BMDMs compared to the other groups, even showing that these cells expressed higher levels of iNOS, and the consequent increased production of $\mathrm{NO}$, an important cell signaling molecule involved in infectious diseases and the death of intracellular pathogens (111), justifying here the reduction in the number of viable bacteria recovered from the vaccinated group. In vivo, IL-6, TNF- $\alpha$, and CD80/CD86 are required for activation of the interferon gamma-producing CD4+ Th1 and CD8+ cytotoxic $\mathrm{T}$ cells, a protective response induced by the host against brucellosis $(81,106,111,112)$. Although our study did not assess the predominant subset of $\mathrm{T}$ cells in the immune response, it is believed that the bactericidal and phagocytic function of macrophages to eliminate the bacteria was mainly enhanced by the secretion of IFN- $\gamma$ and TNF- $\alpha$, since these cytokines showed high expression levels in tissues from immunized animals, suggesting that the Int subunit vaccine predominantly induced an effective Th1 profile response and triggered protection against B. abortus infection (Figure 9).

The information gathered shows that the bioinformatics is a strong approach for vaccine candidate discovery as it offers a faster, cheaper, and safer method to identify potential vaccine targets when compared with traditional laboratory identification methods, particularly when dealing with risk group 3 microorganisms such as Brucella. Here, we provide an RV strategy that was able to identify a $B$. abortus antigen that is found to be strongly associated with bacterial virulence. Thus, immunization with the peptide vaccine had a significant effect on protection against murine infection, inducing an immunoprotected response; therefore, it is plausible to assume that this antigen can form a solid basis for designing an efficient and safe vaccine against animal brucellosis. 


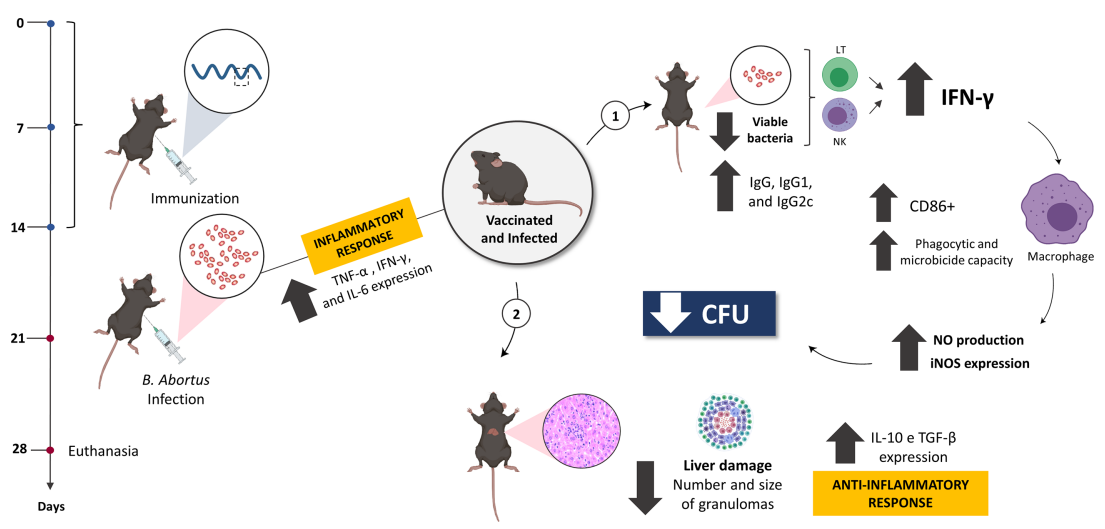

FIGURE 9 | The model proposed in this study suggests the optimal efficacy of the rationally predicted vaccine peptide. After being immunized and challenged, C57BL/6 mice were more resistant to infection by $B$. abortus, with the less systemic recovery of viable bacteria and reduced tissue damage, mediated by an antiinflammatory response. When evaluating the immune response profile, the predominance of characteristic components of the Th1 profile was observed, such as IFN- $\gamma$ and TNF- $\alpha$, suggesting that the vaccine peptide stimulates a profile mediated by CD4+ Th1 lymphocytes to secrete specific components such as IFN- $\gamma$, that mediates the production of NO and acts directly on infected macrophages, enhancing their microbicidal and phagocytic capacity and controlling the spread of systemic infection by this bacterium. Created with BioRender.

\section{DATA AVAILABILITY STATEMENT}

The datasets presented in this study can be found in online repositories. The names of the repository/repositories and accession number(s) can be found below: NCBI BioProject, PRJNA765312.

\section{ETHICS STATEMENT}

The animal study was reviewed and approved by Committee on the Ethics of Animal Experiments (CEUA-UNIFAL 16/2020).

\section{AUTHOR CONTRIBUTIONS}

KO and LAA performed study design. LAA, RS, PC, and SO involved in contribution of study materials. KO, GB, LPA, and EN provided guidance for analytical tools and performed bioinformatic analysis. $\mathrm{KO}$ and NS prepared figures and reagents. KO, GB, and NS performed acquisition and collection of data in vitro and in vivo. $\mathrm{KO}$ and LAA were involved in manuscript preparation. All authors contributed to the article and approved the submitted version.

\section{REFERENCES}

1. Musallam II, Abo-Shehada MN, Hegazy YM, Holt HR, Guitian FJ. Systematic Review of Brucellosis in the Middle East: Disease Frequency in Ruminants and Humans and Risk Factors for Human Infection. Epidemiol Infect (2016) 144:671-85. doi: 10.1017/S0950 268815002575

2. Khurana SK, Sehrawat A, Tiwari R, Prasad M, Gulati B, Shabbir MZ, et al. Bovine Brucellosis - a Comprehensive Review. Veterinary Q (2021) 41(1):61-8. doi: 10.1081/01652176.2020.1868616

3. Pal M, Gizaw F, Fekadu G, Alemayehu G, Kandi V. Public Health and Economic Importance of Bovine Brucellosis: An Overview. Am J Epidemiol Infect Dis (2017) 5(2):27-34. doi: 10.12691/ajeid-5-2-2

\section{FUNDING}

This study was supported in part by the Coordenação de Aperfeiçoamento de Pessoal de Nível Superior-Brasil (CAPES) (Finance Code 001) and Fundação de Amparo à Pesquisa do Estado de Minas Gerais (Grant 864/14) and Universidade Federal de Alfenas and the Brazilian Ministry of Education (MEC) (EDITAL No 002/2020 - PRPPG/REITORIA).

\section{SUPPLEMENTARY MATERIAL}

The Supplementary Material for this article can be found online at: https://www.frontiersin.org/articles/10.3389/fimmu.2021.778475/ full\#supplementary-material

Supplementary Figure 1 | Arrangement of hotspots along the genome of $B$. abortus bacteria expressed during macrophage infection. (A) On chromosome I of $B$. abortus there is the formation of two hotspots characterizing regions of intense mapping of small RNAs and (B) on chromosome II there is the formation of only one hotspot.

Supplementary Figure 2 | Reads and number of each read from the small RNA sequencing.

4. Gortázar C, Ferroglio E, Hofle U, Frolich K, Vicente J. Diseases Shared Between Wildlife and Livestock a European Perspective. Eur J Wildlife Res (2007) 53:241-56. doi: 10.1007/s10344-007-0098-y

5. Franco MP, Mulder M, Gilman RH, Smits HL. Human Brucellosis. Lancet Infect Dis (2007) 7(12):775-86. doi: 10.1016/S1473-3099(07)70286-4

6. Ficht T. Brucella Taxonomy and Evolution. Future Microbiol (2010) 5 (6):859-66. doi: $10.2217 / \mathrm{fmb} .10 .52$

7. Smits HL. Brucellosis in Pastoral and Confined Livestock: Prevention and Vaccination. Rev Scientifique Technique (2013) 32(1):219, 228. doi: 10.20506/ rst.32.1.2200

8. Seleem MN, Boyle SM, Sriranganathan N. Brucellosis: A Re-Emerging Zoonosis. Veterinary Microbiol (2010) 140(3-4):392-8. doi: 10.1016/ j.vetmic.2009.06.021 
9. Dadar M, Shahali Y, Fakhri Y, Godfroid J. The Global Epidemiology of Brucella Infections in Terrestrial Wildlife: A Meta-Analysis. Transboundary Emerg Dis (2020) 2020(00):1-15. doi: 10.111/tbed.13735

10. Franc KA, Krecek RC, Hasler BN, Arenas-Gamboa AM. Brucellosis Remains a Neglected Disease in the Developing World: A Call for Interdisciplinary Action. BMC Public Health (2018) 18(125):1-9. doi: 10.1186/s12889-0175016-y

11. Pappas G, Papadimitriou P, Akritidis N, Christou L, Tsianos EV. The New Global Map of Human Brucellosis. Lancet Infect Dis 6 (2006) 2:91-9. doi: 10.1016/s1437-3099(06)70382-6

12. Hisham Y, Ashhab Y. Identification of Cross-Protective Potential Antigens Against Pathogenic Brucella Spp. Through Combining Pan-Genome Analysis With Reverse Vaccinology. J Immunol Res (2018) 2018 (1474517):1-15. doi: 10.1155/2018/1474517

13. Khan MZ, Zahoor M. An Overview of Brucellosis in Cattle and Humans, and its Serological and Molecular Diagnosis in Control Strategies. Trop Med Infect Dis (2018) 3(2):65. doi: 10.3390/tropicalmed3020065

14. Adone R, Ciuchini F, Marianelli C, Tarantino M, Pistoia C, Marcon G, et al. Protective Properties of Rifampin-Resistant Rough Mutants of Brucella Melitensis. Infection Immun (2005) 73(7):4198-204. doi: 10.1128/ IAI.73.7.4198-4204.2005

15. Goodwin ZI, Pascual DW. Brucellosis Vaccines for Livestock. Veterinary Immunol Immunopathol (2016) 181:51-8. doi: 10.1016/j.vetimm.2016.03.011

16. Saxena HM, Raj S. A Novel Immunotherapy of Brucellosis in Cows Monitored non-Invasively Through a Specific Biomarker. PloS Neglected Trop Dis (2018) 12(4):e0006393. doi: 10.1371/journal.pntd.0006393

17. Pasquevich KA, Estein SM, Samartino CG, Zwerdling A, Coria LM, Barrionuevo P, et al. Immunization With Recombinant Brucella Species Outer Membrane Protein Omp16 or Omp19 in Adjuvant Induces Specific CD4+ and CD8+ T Cells as Well as Systemic and Oral Protection Against Brucella Abortus Infection. Infection Immun (2009) 77(1):436-45. doi: 10.1128/IAI,01151-08

18. Goel D, Rajendran V, Ghosh PC, Bhatnagar R. Cell Mediated Immune Response After Challenge in Omp25 Liposome Immunized Mice Contributes to Protection Against Virulent. Brucella Abortus Vaccine (2013) 54431(8):1231-7. doi: 10.1016/j.vaccine.2012.12.043

19. Mallick AI, Singha H, Chaudhuri P, Nadeem A, Khan SA, Dar KA, et al. Liposomised Recombinant Ribosomal L7/L12 Protein Protects BALB/c Mice Against Brucella Abortus 544 Infections. Vaccine (2007) 25:3692-704. doi: 10.1016/j.vaccine.2007.01.066

20. Grupta S, Mogan S, Somani VK, Aggarwal S, Bhatnagar R. Simultaneous Immunization With Omp25 and L7/L12 Provides Protection Against Brucellosis in Mice. Pathogens (2020) 9(152):1-12. doi: 10.3390/ pathogens 9020152

21. Al-Mariri A, Mahmoud NH, Hammoud R. Efficacy Evaluation of Live Escherichia Coli Expression Brucella P39 Protein Combined With CpG Oligodeoxynucleotides Vaccine Against Brucella Melitensis 16M, in BALB/c Mice. Biologicals (2012) 40(2012):140-5. doi: 10.1016/j.biologicals.2012.01.002

22. Hop HT, Arayan LT, Huy TXN, Reyes AWB, Min W, Lee HJ, et al. Immunization of BALB/c Mice With a Combination of Four Recombinant Brucella Abortus Proteins, AspC, Dps, InpB and Ndk, Confers a Marked Protection Against a Virulent Strain of Brucella Abortus. Vaccine (2018) 36:3027-33. doi: 10.1016/j.vaccine.2018.04.019

23. Ghasemi A, Jeddi-Tehrani M, Mautner J, Salari MH, Zarnani AH. Simultaneous Immunization of Mice With Omp31 and TF Provides Protection Against Brucella Melitensis Infection. Vaccine (2015) 33:55328. doi: $10.1016 /$ j.vaccine.2015.09.013

24. Wang X, Na C, Yang M, Li X, Ke Y, Lei S, et al. Immunization With Individual Proteins of the Lrp/AsnC Family Induces Protection Against Brucella Melitensis 16M Challenges in Mice. Front Immunol (2015) 6:1193 (1193). doi: 10.3389/fmicb.2015.01193

25. Carvalho TF, Haddad JPA, Paixão TA, Santos RL. Meta-Analysis and Advancement of Brucellosis Vaccinology. PloS One (2016) 11:e0166582. doi: 10.1371/journal.pone. 0166582

26. Bao Y, Tian M, Li P, Liu J, Ding C, Yu S. Characterization of Brucella Abortus Mutant Strain $\Delta 22915$, a Potential Vaccine Candidate. Veterinary Res (2017) 48(1):1-13. doi: 10.1186/s13567-017-0422-9
27. Rappuoli R. Reverse Vaccinology. Curr Opin Microbiol (2000) 3(5):445-50. doi: 10.1016/S1369-5274(00)00119-

28. Pizza M, Scarlato V, Masignani V, Giuliani MM, Aricò B, Comanducci M, et al. Identification of Vaccine Candidates Against Serogroup B Meningococcus by Whole-Genome Sequencing. Science (2000) 287 (5459):1816-20. doi: 10.1126/science.287.5459.1816

29. Aslam M, Shehroz M, Shah M, Khan MA, Afridi SG, Khan A. Potential Druggable Proteins and Chimeric Vaccine Construct Prioritization Against Brucella Melitensis From Species Core Genome Data. Genomics (2020) 112 (2):1734-45. doi: 10.1016/j.ygeno.2019.10.009

30. Seib KL, Zhao X, Rappuoli R. Developing Vaccines in the Era of Genomics: A Decade of Reverse Vaccinology. Clin Microbiol Infection (2013) 18 (s5):109-16. doi: 10.1111/j.1469-0691.2012.03939.x

31. Delany I, Rappuoli R, Seib KL. Vaccines, Reverse Vaccinology, and Bacterial Pathogenesis. Cold Spring Harbor Perspect Med (2013) 3(5):a012476. doi: 10.1101/cshperspect.a012476

32. Vishnu US, Sankarasubramanian J, Gunasekaran P, Rajendhran J. Novel Vaccine Candidates Against Brucella Melitensis Identified Through Reverse Vaccinology Approach. OMICS: A J Integr Biol (2015) 19(11):722-9. doi: 10.1089/omi.2015.0105

33. de Almeida LA, Carvalho NB, Oliveira FS, Lacerda TL, Vasconcelos AC, Nogueira L, et al. MyD88 and STING Signaling Pathways are Required for IRF3-Mediated IFN- $\beta$ Induction in Response to Brucella Abortus Infection. PloS One (2011) 6(8):e23135. doi: 10.1371/journal.pone.0023135

34. Martin M. Cutadapt Removes Adapter Sequences From High-Throughput Sequencing Reads. EMBnet J (2011) 17(1):10-2. doi: 10.14806/ej.17.1.200

35. Bolger AM, Lohse M, Usadel B. Trimmomatic: A Flexible Trimmer of Illumina Sequence Data. Bioinformatics (2014) 30(15):2114-20. doi: 10.1093/bioinformatics/btu170

36. Langmead B, Trapnell C, Pop M, Salzberg SL. Ultrafast and MemoryEfficient Alignment of Short DNA Sequences to the Human Genome. Genome Biol (2009) 10(3):R25.1-R25.10. doi: 10.1186/gb-2009-10-3-r25

37. Quinlan AR, Hall IM. BEDTools: A Flexible Suite of Utilities for Comparing Genomic Features. Bioinformatics (2010) 26(6):841-2. doi: 10.1093/ bioinformatics/btp033

38. Yu NY, Wagner JR, Laird MR, Melli G, Rey S, Lo R, et al. PSORTb 3.0: Improved Protein Subcellular Localization Prediction With Refined Localization Subcategories and Predictive Capabilities for All Prokaryotes. Bioinformatics (2010) 26(13):1608-15. doi: 10.1093/bioinformatics/btq249

39. Armenteros JJA, Tsirigos KD, Sonderby CK, Petersen TN, Winther O, Brunak S, et al. SignalP 5.0 Improves Peptide Predictions Using Deep Neural Networks. Nat Biotechnol (2019) 37(4):420-3. doi: 10.1038/s41587-0190036-z

40. Ikeda M, Arai M, Okuno T, Shimizu T. TMPDB: A Database of Experimentally-Characterized Transmembrane Topologies. Nucleic Acids Res (2003) 31(1):406-9. doi: 10.1093/nar/gkg018

41. Mitaku S, Hirokawa T, Tsuji T. Amphiphilicity Index of Polar Amino Acids as Na Aid in the Characterization of Amino Acid Preference at MembraneWater Interfaces. Bioinformatics (2002) 18(4):608-16. doi: 10.1093/ bioinformatics/18.4.608

42. Krogh A, Larsson B, Heijne G, Sonnhammer ELL. Predicting Transmembrane Protein Topology With a Hidden Markov Model: Application to Complete Genomes. J Mol Biol (2001) 305:567-80. doi: $10.1006 /$ jmbi.2000.4315

43. Magrane M, Consortium U. UniProt Knowledgebase: A Hub of Integrated Protein Data. Database (Oxford) (2011) 2011:1-13. doi: 10.1093/database/ bar009

44. Nielsen M, Lund O. NN-Align. An Artificial Neural Network-Based Alignment Algorithm for MHC Class II Peptide Binding Prediction. BMC Bioinf (2009) 10(296):1-10. doi: 10.1186/1471-2105-10-296

45. Rammensee HG, Bachmann J, Emmerich N, Bachor OA, Stevanovic S. SYFPEITHI: Database for MHC Ligands and Peptide Motifs. Immunogenetics (1999) 50:213-9. doi: 10.1007/s002510050595

46. Reche PA, Glutting JP, Zhang H, Reinherz EL. Enhancement to the RANKPEP Resource for the Prediction of Peptide Binding to MHC Molecules Using Profiles. Immunogenetics (2004) 56:405-19. doi: 10.1007/ s00251-004-0709-7 
47. Corpet F. Multiple Sequence Alignment With Hierarchical Clustering. Nucleic Acids Res (1988) 16(22):10881-90. doi: 10.1093/nar/16.22.10881

48. Doytchinova IA, Flower DR. VaxiJen: A Server for Prediction of Protective Antigens, Tumor Antigens and Subunit Vaccines. BMC Bioinf (2007) 8 (4):1-7. doi: 10.1186/1471-2105/8/4

49. Saha S, Raghava GPS. AlgPred: Prediction of Allergenic Proteins and Mapping of IgE Epitopes. Nucleic Acids Res (2006) 34:W202-9. doi: $10.1093 / \mathrm{nar} / \mathrm{gkl} 343$

50. Zai X, Yin Y, Guo F, Yang Q, Li R, Li Y, et al. Screening of Potential Vaccine Candidates Against Pathogenic Brucella Spp. Using Composite Reverse Vaccinology. Veterinary Res (2021) 52(75):1-15. doi: 10.1186/s1356700939-5

51. Gasteiger E, Gattiker A, Hoogland C, Ivanyi I, Appel RD, Bairoch A. ExPASy: The Proteomics Server for in-Depth Protein Knowledge and Analysis. Nucleic Acids Res (2003) 32(3):3784-8. doi: 10.1093/nar/gkg563

52. Kelley LA, Mezulis S, Yates CM, Wass MN, Sternberg MJE. The Phyre2 Web Portal for Protein Modeling, Prediction and Analysis. Nat Protoc (2015) 10 (6):845-58. doi: 10.1038/nprot.2015.053

53. Sanner MF. Python: A Programming Language for Software Integration and Development. J Mol Graphics Modelling 17 (1999) 1:57-61.

54. Ormo M, Cubitt AB, Kallio K, Gross LA, Tsien RY, Remington SJ. Crystal Structure of the Aequores Victoria Green Fluorescent Protein. Science (1996) 273:1392-5. doi: 10.1126/science.273.5280.1392

55. Trott O, Olson AJ. AutoDock Vina: Improving the Speed and Accuracy of Docking With a New Scoring Function, Efficient Optimization, and Multithreading. J Comput Chem (2009) 31:455-61. doi: 10.1002/jcc.21334

56. O’Boyle NM, Banck M, James CA, Morley C, Vandermeersch T, Hutchison GR. Open Babel: An Open Chemical Toolbox. J Cheminformatics (2011) 3 (33):1-14. doi: 10.1186/1758-2946-3-3

57. Laskowski RA, Swindells MB. LigPlot+: Multiple Ligand-Protein Interaction Diagrams for Drug Discovery. J Chem Inf Modeling (2011) 51:2778-86. doi: $10.1021 / \mathrm{ci} 200227 \mathrm{u}$

58. Rigsby R, Parker AB. Using the PyMOL Application to Reinforce Visual Understanding of Protein Structure. Biochem Mol Biol Educ (2016) 44 (5):433-7. doi: 10.1002/bmb.20966

59. Gomes MT, Campos PC, Pereira GDS, Bartholomeu DC, Splitter G, Oliveira SC. TLR9 is Required for MAPK/NF-kb Activation But Does Not Cooperate With TLR2 or TLR6 to Induce Host Resistance to Brucella Abortus. J Leukocyte Biol (2016) 99(5):771-80. doi: 10.1189/jlb.4A0815-346R

60. Xavier MN, Paixão TA, Poester FP, Lage AP, Santos RL. Pathological, Immunohistochemical and Bacteriological Study of Tissues and Milk of Cows and Fetuses Experimentally Infected With Brucella Abortus. J Comp Pathol (2009) 140(2-3):149-57. doi: 10.1016/j.jcpa.2008.10.004

61. Brandão AP, Oliveira FS, Carvalho NB, Vieira LQ, Azevedo V, Macedo GC, et al. Host Susceptibility to Brucella Abortus Infection is More Pronounced in IFN- $\gamma$ Knockout Than IL-12/ß2-Microglobulin Double-Deficient Mice. Clin Dev Immunol (2012) 2012:589494. doi: 10.1155/2012/589494

62. Stranahan LW, Khalaf OH, Garcia-Gonzalez DG, Arenas-Gamboa AM. Characterization of Brucella Canis Infection in Mice. PloS One (2019) 14(6): e0218809. doi: 10.1371/journal.pone.02118809

63. Giambartolomei GH, Delpino MV. Immunopathogenesis of Hepatic Brucellosis. Front Cell Infection Microbiol (2019) 9:(423). doi: 10.3389/ fcimb.2019.00423

64. Avila-Calderón ED, Lopez-Merino A, Sriranganathan N, Boyle SM, ContrerasRodríguez A. A History of the Development of Brucella Vaccines. BioMed Res Int (2013) 2013(743509):1-8. doi: 10.1155/2013/743509

65. Olsen SC. Recent Developments in Livestock and Wildlife Brucellosis Vaccination. Rev Scientifique Technique (International Office Epizootics) (2013) 32(1):207-17. doi: 10.20506/rst.32.1.2201

66. Schurig GG, Sriranganathan N, Corbel MJ. Brucellosis Vaccines: Past, Present and Future. Veterinary Microbiol (2002) 90(1-4):479-96. doi: 10.1016/S0378-1135(02)00255-9

67. Yang X, Skyberg JA, Cao L, Clapp B, Thornburg T, Pascual DW. Progress in Brucella Vaccine Development. Front Biol (2013) 8(1):60-77. doi: 10.1007/ s11515-012-1196-0

68. Zhao Z, Yan F, Ji W, Luo D, Liu X, Xing L, et al. Identification of Immunoreactive Proteins of Brucella Melitensis by Immunoproteomics. Sci China Life Sci (2011) 54(9):880-7. doi: 10.1007/s11427-011-4218-2
69. Yang Y, Wang L, Yin J, Wang X, Cheng S, Lang X, et al. Immunoproteomic Analysis of Brucella Melitensis and Identification of a New Immunogenic Candidate Protein for the Development of Brucellosis Subunit Vaccine. Mol Immunol (2011) 49(1-2):175-84. doi: 10.1016/j.molimm.2011.08.009

70. Sternon JF, Godessart P, Gonçalves de Freitas R, van der Henst M, Poncin K, Francis N, et al. Transposon Sequencing of Brucella Abortus Uncovers Essential Genes for Growth In Vitro and Inside Macrophages. Infection Immun (2018) 86(8):e00312-18. doi: 10.1128/IAI.00312-18

71. Goolab S, Roth RL, Van Heerden H, Crampton MC. Analyzing the Molecular Mechanism of Lipoprotein Localization in Brucella. Front Microbiol (2015) 6:1189(1189). doi: 10.3389/fmicb.2015.01189

72. Oliveira SC, Splitter GA. Immunization of Mice With Recombinant L7L12 Ribosomal Protein Confers Protection Against Brucella Abortus Infection. Vaccine (1996) 14(10):959-62. doi: 10.1016/0264-410X(96)00018-7

73. Cassataro J, Estein SM, Pasquevich KA, Velikovsky CA, de la Barrera S, Bowden R, et al. Vaccination With the Recombinant Brucella Outer Membrane Protein 31 or a Derived 27-Amino-Acid Synthetic Peptide Elicits a CD4+ T Helper 1 Response That Protects Against Brucella Melitensis Infection. Infection Immun (2005) 73(12):8079-88. doi: 10.1128/IAI.73.12.8079-8088.2005

74. Yang X, Walters N, Robison A, Trunkle T, Pascual DW. Nasal Immunization With Recombinant Brucella Melitensis Bp26 and Trigger Factor With Cholera Toxin Reduces B. Melitensis Colonization. Vaccine (2007) 25(12):2261-8. doi: 10.1016/j.vaccine.2006.12.004

75. Goel D, Bhatnagar R. Intradermal Immunization With Outer Membrane Protein 25 Protects Balb/c Mice From Virulent Brucella Abortus 544. Mol Immunol (2012) 51(2):159-68. doi: 10.1016/j.molimm.2012.02.126

76. Paul S, Peddayelachagiri BV, Nagaraj S, Kingston JJ, Batra HV. Recombinant Outer Membrane Protein 25c From Brucella Abortus Induces Th1 and Th2 Mediated Protection Against Brucella Abortus Infection in Mouse Model. Mol Immunol (2018) 99:9-18. doi: 10.1016/j.molimm.2018.04.002

77. Huy TXN, Nguyen TT, Reyes AWB, Vu SH, Min W, Lee HJ, et al. Immunization With a Combination of Four Recombinant Brucella Abortus Proteins Omp16, Omp19, Omp28, and L7/L12 Induces T Helper 1 Immune Response Against Virulent B. Abortus 544 Infection in BALB/C Mice. Front Veterinary Sci (2021) 7:577026. doi: 10.3389/fvets.2020.577026

78. Mraheil MA, Billion A, Mohamed W, Mukherjee K, Kuenne C, Pischimarov J, et al. The Intracellular sRNA Transcriptome of Listeria Monocytogenes During Growth in Macrophages. Nucleic Acids Res (2011) 39(10):4235-48. doi: $10.1093 /$ nar/gkr033

79. Ko KY, Kim JW, Her M, Kang SI, Jung SC, Cho DH, et al. Immunogenic Proteins of Brucella Abortus to Minimize Cross Reactions in Brucellosis Diagnosis. Veterinary Microbiol (2012) 156(3-4):374-80. doi: 10.1016/ j.vetmic.2011.11.011

80. Hanna N, Ouahrani-Bettache S, Drake KL, Adams LG, Köhler S, Occhialini A. Global Rsh-Dependent Transcription Profile of Brucella Suis During Stringent Response Unravels Adaptation to Nutrient Starvation and CrossTalk With Other Stress Responses. BMC Genomics (2013) 14(1):1-16. doi: 10.1186/1471-2164-14-459

81. Ahmed W, Zheng K, Liu ZF. Establishment of Chronic Infection: Brucella's Stealth Strategy. Front Cell Infection Microbiol (2016) 6:30(30). doi: 10.3389/ fcimb.2016.00030

82. Corsetti PP, de Almeida LA, Gonçalves ANA, Gomes MTR, Guimarães ES, Marques JT, et al. miR-181a-5p Regulates TNF- $\alpha$ and miR-21a-5p Influences Gualynate-Binding Protein 5 and IL-10 Expression in Macrophages Affecting Host Control of Brucella Abortus Infection. Front Immunol 9 (2018) 1331:1331. doi: 10.3389/fimmu.2018.01331

83. Caswell CC, Gaines JM, Ciborowski P, Smith D, Borchers CH, Roux CM, et al. Identification of Two Small Regulatory RNAs Linked to Virulence in Brucella Abortus 2308. Mol Microbiol (2012) 85(2):345-60. doi: 10.1111/ j.1365-2958.2012.08117.x

84. Dong H, Peng X, Wang N, Wu Q. Identification of Novel sRNAs in Brucella Abortus 2308. FEMS Microbiol Lett (2014) 354(2):119-25. doi: 10.1111/ 1574-6968.12433

85. Herrou J, Willet JW, Fiebig A, Czyż DM, Cheng JX, Ultee E, et al. Brucella Periplasmic Protein EipB is a Molecular Determinant of Cell Envelope Integrity and Virulence. J Bacteriol (2019) 201(12):e00134-19. doi: 10.1128/ JB.00134-19 
86. Lapaque N, Moriyon I, Moreno E, Gorvel JP. Brucella Lipopolysaccharide Acts as a Virulence Factor. Curr Opin Microbiol (2005) 8(1):60-6. doi: 10.1016/j.mib.2004.12.003

87. Cardoso PG, Macedo GC, Azevedo V, Oliveira SC. Brucella Spp. Noncanonical LPS: Structure, Biosynthesis, and Interaction With Host Immune System. Microbial Cell Factories (2006) 5(1):1-11. doi: 10.1186/ 1475-2859-5-13

88. Forestier C, Moreno E, Pizarro-Cerda J, Gorvel JP. Lysosomal Accumulation and Recycling of Lipopolysaccharide to the Cell Surface of Murine Macrophages, an In Vitro and In Vivo Study. J Immunol (1999) 162(11):6784-91.

89. Moreno E, Berman DT, Boettcher LA. Biological Activities of Brucella Abortus Lipopolysaccharides. Infection Immun (1981) 31(1):362-70. doi: 10.1128/iai.31.1.362-370.1981

90. Forestier C, Deleuil F, Lapaque N, Moreno E, Gorvel JP. Brucella Abortus Lipopolysaccharide in Murine Peritoneal Macrophages Acts as a DownRegulator of T Cell Activation. J Immunol (2000) 165(9):5202-10. doi: 10.4049/jimmunol.165.9.5202

91. Pasquevich KA, Ibañez AE, Coria LM, García Samartino C, Estein SM, Zwerdling A, et al. An Oral Vaccine Based on U-Omp19 Induces Protection Against B. Abortus Mucosal Challenge by Inducing an Adaptive IL-17 Immune Response in Mice. PloS One (2011) 6(1):e16203. doi: 10.1371/ journal.pone.0016203

92. Lim JJ, Kim DH, Lee JJ, Kim DG, Min W, Lee HJ, et al. Protective Effects of Recombinant Brucella Abortus Omp28 Against Infection With a Virulent Strain of Brucella Abortus 544 in Mice. J Veterinary Sci (2012) 13(3):287-92. doi: $10.4142 /$ jvs.2012.13.3.287

93. Lacerda TLS, Cardoso PG, De Almeida LA, da Cunha Camargo ILB, Afonso DAF, Trant CC, et al. Inactivation of Formyltransferase (Wbkc) Gene Generates a Brucella Abortus Rough Strain That is Attenuated in Macrophages and in Mice. Vaccine (2010) 28(34):5627-34. doi: 10.1016/ j.vaccine.2010.06.023

94. Lalsiamthara J, Kaur G, Gogia N, Ali SA, Goswami TK, Chaudhuri P. Brucella Abortus S19 rfbD Mutant is Highly Attenuated, DIVA Enable and Confers Protection Against Virulent Challenge in Mice. Biologicals (2020) 63:62-7. doi: 10.1016/j.biologicals.2019.11.005

95. Vitry MA, Mambres DH, De Trez C, Akira S, Ryffel B, Letesson JJ, et al. Humoral Immunity and CD4+ Th1 Cells are Both Necessary for a Fully Protective Immune Response Upon Secondary Infection With Brucella Melitensis. J Immunol (2014) 192(8):3740-52. doi: 10.4049/jimmunol.1302561

96. Clausse M, Díaz AG, Ghersi G, Zylberman V, Cassataro J, Giambartolomei GH, et al. The Vaccine Candidate BLSOmp31 Protects Mice Against Brucella Canis Infection. Vaccine (2013) 31(51):6129-35. doi: 10.1016/j.vaccine.2013.07.041

97. Golshani M, Rafati S, Nejati-Moheimani M, Ghasemian M, Bouzari S. Comparison of Potential Protection Conferred by Three Immunization Strategies (Protein/Protein, DNA/DNA, and DNA/protein) Against Brucella Infection Using Omp2b in BALB/c Mice. Veterinary Microbiol (2016) 197:47-52. doi: 10.1016/j.vetmic.2016.10.027

98. Enright FM, Araya LN, Elzer PH, Rowe GE, Winter AJ. Comparative Histopathology in BALB/c Mice Infected With Virulent and Attenuated Strains of Brucella Abortus. Veterinary Immunol Immunopathol (1990) 26 (2):171-82. doi: 10.1016/0165-2427(90)90065-Z

99. Corsetti PP, de Almeida LA, Carvalho NB, Azevedo V, Silva TM, Teixeira HC, et al. Lack of Endogenous IL-10 Enhances Production of Proinflammatory Cytokines and Leads to Brucella Abortus Clearance in Mice. PloS One (2013) 8(9):e74729. doi: 10.1371/journal.pone.0074729

100. Xavier MN, Winter MG, Spees AM, Nguyen K, Atluri VL, Silva TM, et al. CD4+ T Cell-Derived IL-10 Promotes Brucella Abortus Persistence via Modulation of Macrophage Function. PloS Pathog (2013) 9(6):e1003454. doi: 10.1371/journal.ppat.1003454
101. Saraiva M, O'garra A. The Regulation of IL-10 Production by Immune Cells. Nat Rev Immunol (2010) 10(3):170-81. doi: 10.1038/nri2711

102. Belo VA, Pereira JA, Souza SFD, de Lima Tana F, Pereira BP, de Oliveira Lopes D, et al. The Role of IL-10 in Immune Responses Against Pseudomonas Aeruginosa During Acute Lung Infection. Cell Tissue Res (2021) 383(3):1123-33. doi: 10.1007/s00441-020-03308-4

103. Martirosyan A, Moreno E, Gorvel JP. An Evolutionary Strategy for a Stealthy Intracellular Brucella Pathogen. Immunol Rev (2011) 240(1):211-34. doi: 10.1111/j.1600-065X.2010.00982.x

104. Durward M, Radhakrishnan G, Harms J, Bareiss C, Magnani D, Splitter GA. Active Evasion of CTL Mediated Killing and Low Quality Responding CD8+ T Cells Contribute to Persistence of Brucellosis. PloS One (2012) 7(4):e34925. doi: 10.1371/journal.pone.0034925

105. Murphy EA, Asselan JS, Parent MA, Zou B, Baldwin CL. Interferon- $\gamma$ is Crucial for Surviving a Brucella Abortus Infection in Both Resistant C57BL/6 and Susceptible BALB/c Mice. Immunology (2001) 2001(103):511-8. doi: 10.1046/j.1365-2567.2001.01258.x

106. Vitry MA, De Trez C, Goriely S, Dumoutier L, Akira S, Ryffel B, et al. Crucial Role of Gamma Interferon-Producing CD4+ Th1 Cells But Dispensable Function of CD8+ T Cell, B Cell, Th2, and Th17 Responses in the Control of Brucella Melitensis Infection in Mice. Infection Immun (2012) 80(12):4271-80. doi: 10.1128/IAI.00761-12

107. Zhan Y, Cheers C. Control of IL-12 and IFN- $\gamma$ Production in Response to Live or Dead Bacteria by TNF and Other Factors. J Immunol (1998) 161 (3):1447-53.

108. Hop HT, Huy TXN, Reyes AWB, Arayan LT, Vu SH, Min W, et al. Interleukin 6 Promotes Brucella Abortus Clearance by Controlling Bactericidal Activity of Macrophages and CD8+ T Cell Differentiation. Infection Immun (2019) 87(11):e00431-19. doi: 10.1128/IAI.00431-19

109. Guimarães ES, Martins JM, Gomes MTR, Cerqueira DM, Oliveira SC. Lack of Interleukin-6 Affects IFN- $\gamma$ and TNF- $\alpha$ Production and Early In Vivo Control of Brucella Abortus Infection. Pathogens (2020) 9(12):1040. doi: $10.3390 /$ pathogens 9121040

110. Hu H, Tian M, Li P, Guan X, Lian Z, Yin Y, et al. Brucella Infection Regulates Thioredoxin-Interacting Protein Expression to Facilitate Intracellular Survival by Reducing the Production of Nitric Oxide and Reactive Oxygen Species. J Immunol (2020) 204(3):632-43. doi: 10.4049/jimmunol.1801550

111. Skendros P, Boura PJRST. Immunity to Brucellosis. Rev Scientifique Technique (2013) 32(1):137-47. doi: 10.20506/rst.32.1.2190

112. Dorneles EM, Sriranganathan N, Lage AP. Recent Advances in Brucella Abortus Vaccines. Veterinary Res (2015) 46(1):1-10. doi: 10.1186/s13567-015-0199-7

Conflict of Interest: The authors declare that the research was conducted in the absence of any commercial or financial relationships that could be construed as a potential conflict of interest.

Publisher's Note: All claims expressed in this article are solely those of the authors and do not necessarily represent those of their affiliated organizations, or those of the publisher, the editors and the reviewers. Any product that may be evaluated in this article, or claim that may be made by its manufacturer, is not guaranteed or endorsed by the publisher.

Copyright (๑) 2021 Oliveira, Brancaglion, Santos, Araújo, Novaes, Santos, Oliveira, Corsetti and de Almeida. This is an open-access article distributed under the terms of the Creative Commons Attribution License (CC BY). The use, distribution or reproduction in other forums is permitted, provided the original author(s) and the copyright owner(s) are credited and that the original publication in this journal is cited, in accordance with accepted academic practice. No use, distribution or reproduction is permitted which does not comply with these terms. 